\title{
Ictiofauna do Parque Nacional da Serra da Bodoquena, Mato Grosso do Sul, Brasil: composição e subsídios à conservação
}

\author{
Maria José Alencar Vilela ${ }^{1 *}$ \\ Francisco de Paula Severo Neto ${ }^{2}$ \\ Otávio Froehlich ${ }^{\dagger}$ \\ Fernando Rogério Carvalho ${ }^{2}$ \\ ${ }^{1}$ Universidade Federal de Mato Grosso do Sul, Campus Três Lagoas \\ Avenida Ranulpho Marques Leal, 3.484, CEP 79.613-000, Três Lagoas - MS, Brasil \\ ${ }^{2}$ Universidade Federal de Mato Grosso do Sul, Cidade Universitária \\ Avenida Costa e Silva, s/n, Bairro Universitário, CEP 79.070-900, Campo Grande - MS, Brasil \\ $\dagger$ In memoriam \\ * Autor para correspondência \\ mjavilela@yahoo.com.br
}

Submetido em 06/08/2020

Aceito para publicação em 04/03/2021

\section{Resumo}

A Serra da Bodoquena abarca cabeceiras de importantes rios da bacia do alto Paraguai e constitui um dos mais extensos conjuntos cársticos do Brasil. Conhecida como importante destino turístico do Brasil, desde 2000 a região conta com o Parque Nacional da Serra da Bodoquena (PNSB). Apresentamos aqui a ictiofauna e a descrição dos principais sistemas hídricos do PNSB, a partir de levantamentos efetuados em agosto-setembro e dezembro de 2005, com uso de redes de arrasto e espera e com pesca elétrica. Para a lista de espécies acrescentamos registros efetuados em estudos posteriores, resultando em 60 espécies, pertencentes a sete ordens e 21 famílias, todas autóctones do alto rio Paraguai, com exceção da tilápia Coptodon rendalli, única não nativa. A riqueza foi maior na bacia do rio Salobra (49 espécies, 39 exclusivas), em comparação com a bacia do rio Perdido (15 espécies, seis exclusivas). Documentamos sete espécies endêmicas da Serra da Bodoquena, duas ameaçadas de extinção (categoria Vulnerável): Trichomycterus dali e Ancistrus formoso. Como medidas mitigatórias e preventivas de impactos indicamos a regularização da situação fundiária e o incremento de programas de educação ambiental, como formas de subsidiar políticas públicas que colaborem para a conservação dos sistemas aquáticos e suas comunidades bióticas.

Palavras-chave: Alto rio Paraguai; Endemismo; Inventário faunístico; Rios cársticos

\section{Abstract}

Ichthyofauna in Serra da Bodoquena National Park, Mato Grosso do Sul State, Brazil: composition and conservation measures. The Serra da Bodoquena includes the headwaters of important rivers of the upper Paraguay River basin and constitutes one of the more extensive karst formations in Brazil. The region is an important tourist destination and Serra da Bodoquena National Park (SBNP) was established in 2000. In 
this work, we provide a list of the ichthyofauna and describe the main water systems in SBNP. Surveys were carried out in August, September and December 2005 using trawl nets, gill nets and electrofishing. For the list of species, we included records made in subsequent studies, resulting in 60 species belonging to seven orders and 21 families, which are all autochthonous to the upper Paraguay River, except the tilapia Coptodon rendalli, the only non-native species. The species richness was higher in the Salobra River basin (49 species, 39 exclusive) compared to the Perdido River basin (15 species, six exclusive). We documented seven endemic species in the Serra da Bodoquena, of which two are threatened with extinction (Vulnerable category): Trichomycterus dali and Ancistrus formoso. As mitigation and preventive measures for environmental impacts, we suggest regularizing land use and increasing environmental education programs as ways of contributing to public policies that are involved in the conservation of aquatic systems and their biotic communities.

Key words: Endemism; Faunistic inventory; Karstic rivers; Upper Paraguay River

\section{Introdução}

A Serra da Bodoquena é composta por um planalto escarpado de natureza cárstica, com aproximadamente $200 \mathrm{~km}$ de extensão em direção norte-sul e altitudes de até 800 m (BOGGIANI et al., 1993; SALLUN FILHO; KARMANN, 2007), localizada no centro-sul do Mato Grosso do Sul, totalmente inserida na bacia hidrográfica do alto rio Paraguai (SALLUN FILHO et al., 2009; ICMBIO, 2013a). Nessa região, encontra-se o Parque Nacional da Serra da Bodoquena (PNSB), criado em setembro de 2000 (PR, 2000). Trata-se de uma Unidade de Conservação (UC) de Proteção Integral, cujos principais objetivos são a preservação de ecossistemas naturais, a realização de pesquisas científicas, o desenvolvimento de atividades de educação e interpretação ambiental, de recreação e turismo ecológico (BRASIL, 2000).

Pelas suas peculiaridades históricas, geomorfológicas e geoquímicas, os ambientes aquáticos da região são propícios ao desenvolvimento de sistemas únicos, com grandes possibilidades de abrigar espécies endêmicas (BENINE et al., 2004; UETANABARO et al., 2007; CARVALHO et al., 2018).

Apesar da riqueza e singularidade, foi somente a partir da década de 1990 que a região passou a receber efetivo interesse por parte da comunidade científica, com o desenvolvimento de trabalhos que resultaram em uma série de publicações (BOGGIANI et al., 1993; SABINO; TRAJANO, 1997; BRITSKI et al., 1999; SABINO; SAZIMA 1999; SCREMIN-DIAS et al., 1999; SABINO; ANDRADE, 2003; BENINE et al., 2004; REYS et al., 2005; SEVERO-NETO et al.,
2015). Expedições de pesquisa também contribuíram para o conhecimento da ictiofauna da região. Entre elas destacam-se: a) AquaRAP (AQUATIC RAPID ASSESSMENT PROGRAM), realizada em 1998 e direcionada aos ecossistemas aquáticos do Pantanal, com alguns pontos amostrados em cabeceiras e tributários dos rios da Prata, Formoso e Salobra, que resultou no registro de 17 espécies não descritas (MENEZES et al., 2000; WILLINK et al., 2000); b) expedição interinstitucional organizada em 2004 por pesquisadores da Universidade de São Paulo, Universidade Federal de Mato Grosso do Sul, Universidade para o Desenvolvimento do Estado e Região do Pantanal e Smithsonian Institution, que realizaram um inventário voltado para ambientes da Serra da Bodoquena, cujo material encontra-se depositado na coleção de peixes do Laboratório de Ictiologia de Ribeirão Preto - LIRP; e c) diagnóstico geral sobre a ictiofauna da bacia do rio Miranda, vinculado ao programa Biota-MS, com inclusão de pontos de coleta na Serra da Bodoquena (FERREIRA et al., 2017).

No entanto, o inventário mais diretamente voltado para o PNSB ocorreu em 2005, durante a Avaliação Ecológica Rápida (AER), organizada pelo Instituto Chico Mendes de Conservação da Biodiversidade (ICMBIO), para elaborar o Plano de Manejo do PNSB. Neste trabalho são apresentados os resultados sobre a distribuição e composição da ictiofauna nos principais sistemas aquáticos da UC, incluindo a descrição dos ambientes e uma breve discussão sobre as principais ameaças à conservação da ictiofauna e possíveis medidas para sua mitigação. 


\section{Material e Métodos}

\section{Área de estudo}

O PNSB situa-se entre as coordenadas $21^{\circ} 08^{\prime} 02^{\prime \prime} \mathrm{S}$ $20^{\circ} 38^{\prime} 26^{\prime \prime} \mathrm{S}$ e $56^{\circ} 48^{\prime} 31^{\prime \prime} \mathrm{W} 56^{\circ} 44^{\prime} 28^{\prime \prime} \mathrm{W}$, ocupando uma área de 76.481 ha, separada em duas seções: uma ao norte, com 27.793 ha, e outra ao sul, com 48.688 ha (Figura 1). Está inserido no bioma Cerrado, com uma estação seca entre maio e setembro e uma chuvosa, de outubro a abril, quando as precipitações oscilam entre 1.000 e $2.000 \mathrm{~mm}$ (ICMBIO, 2013a).

FIGURA 1: Mapa do Parque Nacional da Serra da Bodoquena, com as principais drenagens. Círculos coloridos indicam os sítios amostrais durante as campanhas da Avaliação Ecológica Rápida: Verde - I, Rancho Branco; Alaranjado - II, Remanso; Amarelo - III, Laudejá; Vermelho - IV, Harmonia; Azul - V, Campo Verde. Círculos pretos - outros levantamentos. Linha preta - limites do PNSB. A estrela ao norte representa Bodoquena, ao sul, Bonito. A estrela superior representa Bodoquena; a inferior, Bonito.

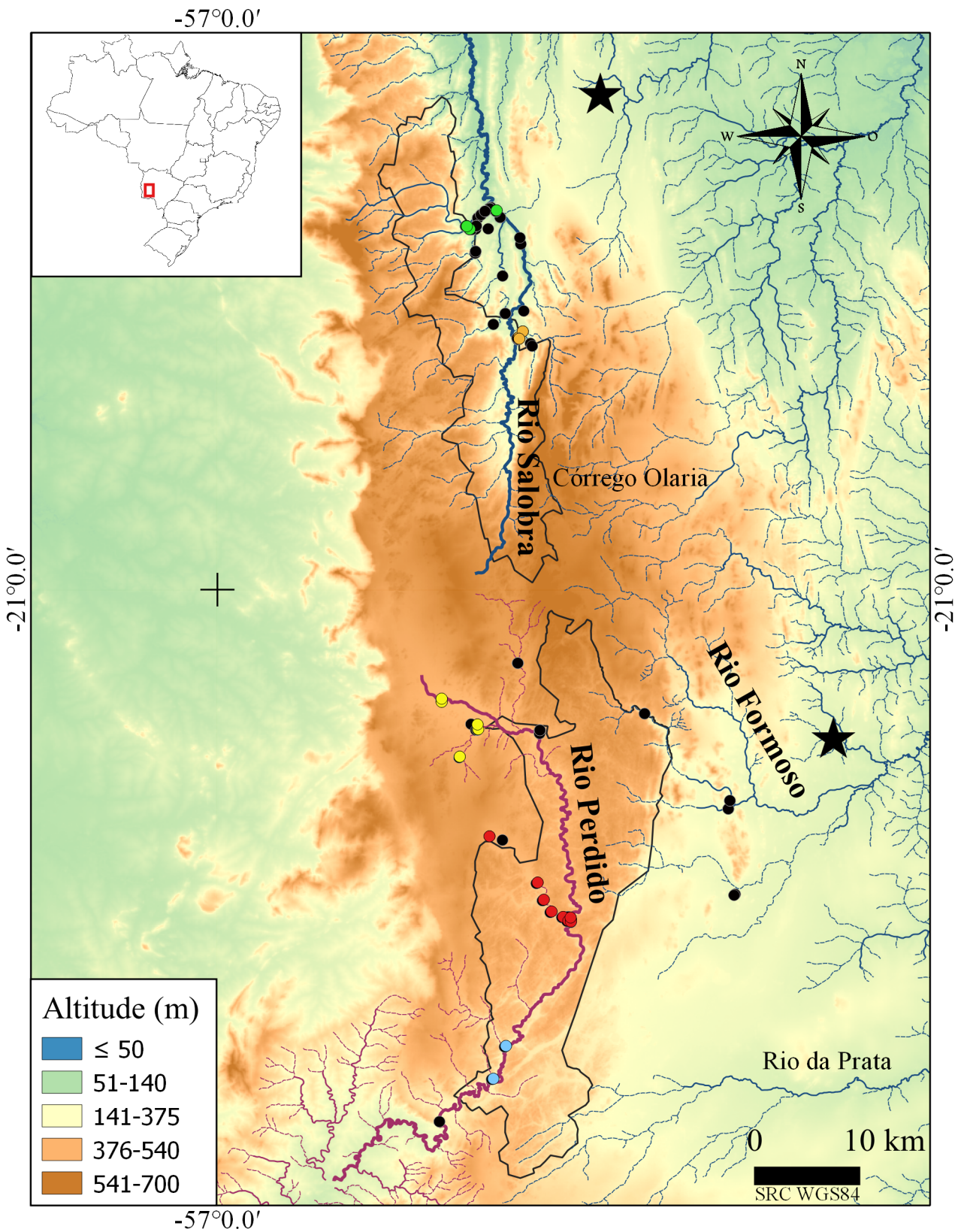

* Fonte para confecção da imagem: "The CGIAR Consortium for Spatial Information (CGIAR-CSI)", disponível em http://srtm.csi.cgiar. org/ e http://www.snirh.gov.br/hidroweb/. 
A formação cárstica da região favorece a formação de rios encaixados, além de feições peculiares ao longo das drenagens, como os sumidouros, as surgências (ou ressurgências) e as tufas calcárias, consideradas as mais extensas e ricas formações da América do Sul, com datação de até 5.200 anos A.P. (SALLUN FILHO et al., 2004; 2009). Assim, no leito dos rios e riachos, são comuns os dutos subterrâneos e as surgências, resultando em frequentes cursos intermitentes, sobretudo na estação seca. As tufas são formadas devido ao alto teor de bicarbonato de cálcio e às associações de musgos e cianofíceas (SALLUN FILHO et al., 2009). Esse material se deposita sobre raízes, troncos e rochas, criando barreiras que, ao longo do tempo, formam sequências intercaladas de cachoeiras e poções nos rios e córregos (Figura 2).

Os corpos d'água do PNSB estão inseridos em cinco microbacias (ICMBIO, 2013b): rios Salobra e Olaria, no setor norte, e rios Perdido, Prata e Formoso, na porção sul (Figura 1). Os três maiores são descritos a seguir e foram trabalhados no presente estudo.

Bacia do rio Salobra. O rio Salobra atravessa parte do fragmento norte do PNSB e deságua no rio Miranda, na planície pantaneira. Dentro do PNSB, flui por vales profundos com águas cristalinas e substrato composto por seixos rolados, blocos, matacões e extensos lajedos, que são afloramentos rochosos inteiriços, em uma sucessão de corredeiras, pequenas quedas e poções, onde o fluxo mais lento permite depósitos de areia e folhiço. Sobre as tufas e blocos rochosos da calha do rio é comum o desenvolvimento de plantas como as floridas Gloxinia sylvatica e tufos do arbusto sarã Phyllanthus sellowianus (ICMBIO, 2013b) (Figura 3). Dentro da UC as margens do rio têm florestas ripárias preservadas, mas externamente são comuns os trechos onde foram parcialmente substituídas por pastagem, plantios agrícolas e bambuzais, com predomínio de Guadua cf. chacoensis (ICMBIO, 2013b).

FIGURA 2: Formações típicas da região da Bodoquena: a. Sumidouro e b. Ressurgência no córrego Santa Maria; c. Tufas calcárias no córrego Taquaral, na estiagem; d. Paredão rochoso e mata ripária no rio Salobra.

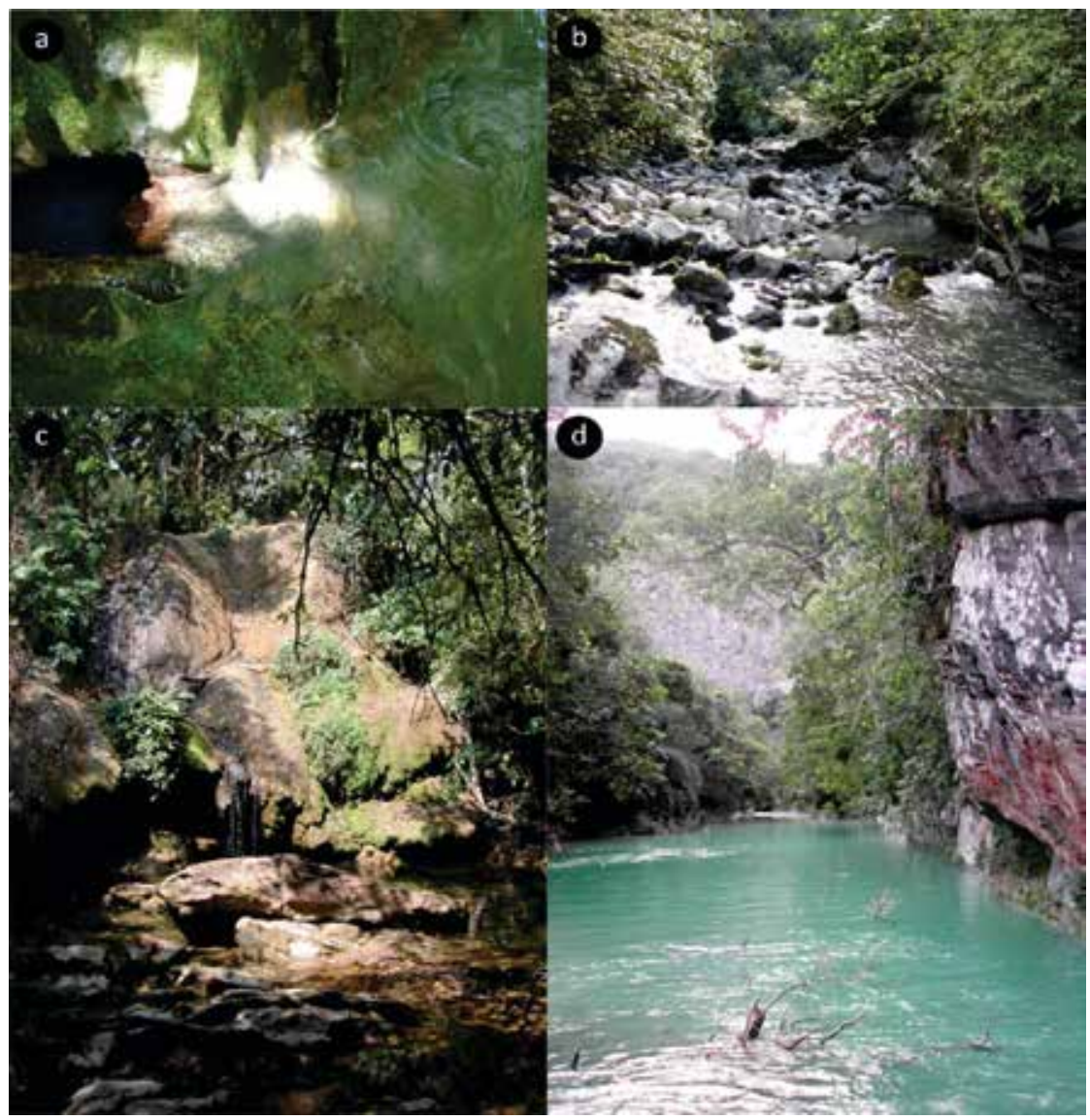


FIGURA 3: Ambientes aquáticos no rio Salobra: a. Lajedo e poção (ao fundo); b. Pequenas cachoeiras formadas por tufas calcárias; c. Bambuzal na margem direita; d. Rio na estação chuvosa.

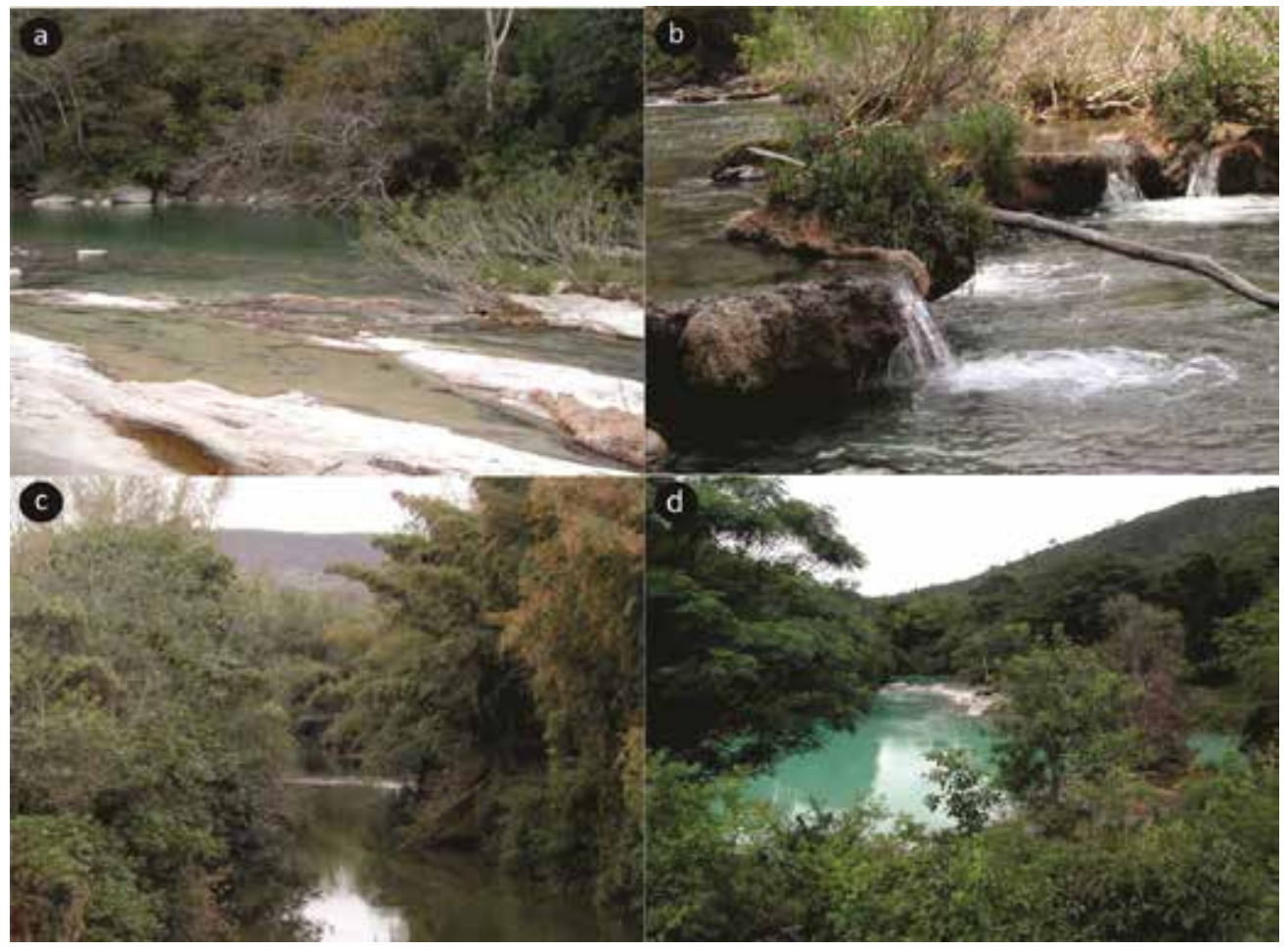

Afluente do rio Salobra, o córrego Salobrinha corre encaixado em vales estreitos, com relevo acidentado e florestas ripárias bem preservadas. Possui águas límpidas e transparentes, que se turvam apenas após chuvas fortes, quando o nível da água pode subir rapidamente, chegando a mais de $2 \mathrm{~m}$ em algumas situações. $\mathrm{Na}$ estiagem são comuns os trechos intermitentes. O substrato é tipicamente rochoso, com seixos e matacões no leito e acúmulo de folhiço e areia nos poções (Figura 4).

FIGURA 4: Córrego Salobrinha: a. Durante a estação chuvosa; b. Leito na estação seca.

Bacia do rio Perdido. No fragmento sul do PNSB, o rio Perdido tem nascentes em altitudes elevadas (560 m) e, nos primeiros $20 \mathrm{~km}$ de sua extensão, entra em terreno plano e forma uma grande área alagada conhecida como "banhado do Perdido", parcialmente localizada nas terras que separam os dois fragmentos do PNSB. Na região do banhado a água é transparente, mas turva-se com facilidade, em razão da espessa camada de sedimentos finos de cor branco/amarelada depositados no substrato, onde se desenvolvem extensas forrações de algas Characeae, que, segundo Boggiani (1999), contribuem para o aporte de material biológico aos detritos de fundo (Figura 5). Nas áreas com maior profundidade, que podem chegar a mais de $2 \mathrm{~m}$ no período chuvoso, forma-se uma densa cobertura flutuante de gramíneas aquáticas, com predomínio do capim-navalha Cladium spp. (ICMBIO, 2013b). No período seco, as áreas mais rasas do banhado podem secar, restringindo-se a pequenos filetes de água que correm entre lagoas remanescentes.

A jusante do banhado, o rio Perdido desaparece num sumidouro e reaparece poucos quilômetros adiante, passando a correr encaixado entre paredões rochosos, cobertos por matas bem preservadas, com uma sucessão de tufas calcárias que formam grandes quedas e separam trechos profundos (geralmente com mais de $6 \mathrm{~m}$ ) de correnteza média (Figura 6). Na porção mais meridional da bacia as florestas ripárias foram parcialmente substituídas por bambuzais e pastagens. Muitos de seus tributários são temporários e secam completamente na época da estiagem.

FIGURA 5: Ambientes aquáticos no Banhado do rio Perdido: a. Lagoa com macrófitas submersas e bancos de capim-navalha, período chuvoso; b. Área seca na estiagem; c. Poço escavado pela água em trilhas de gado, com sedimento argiloso.

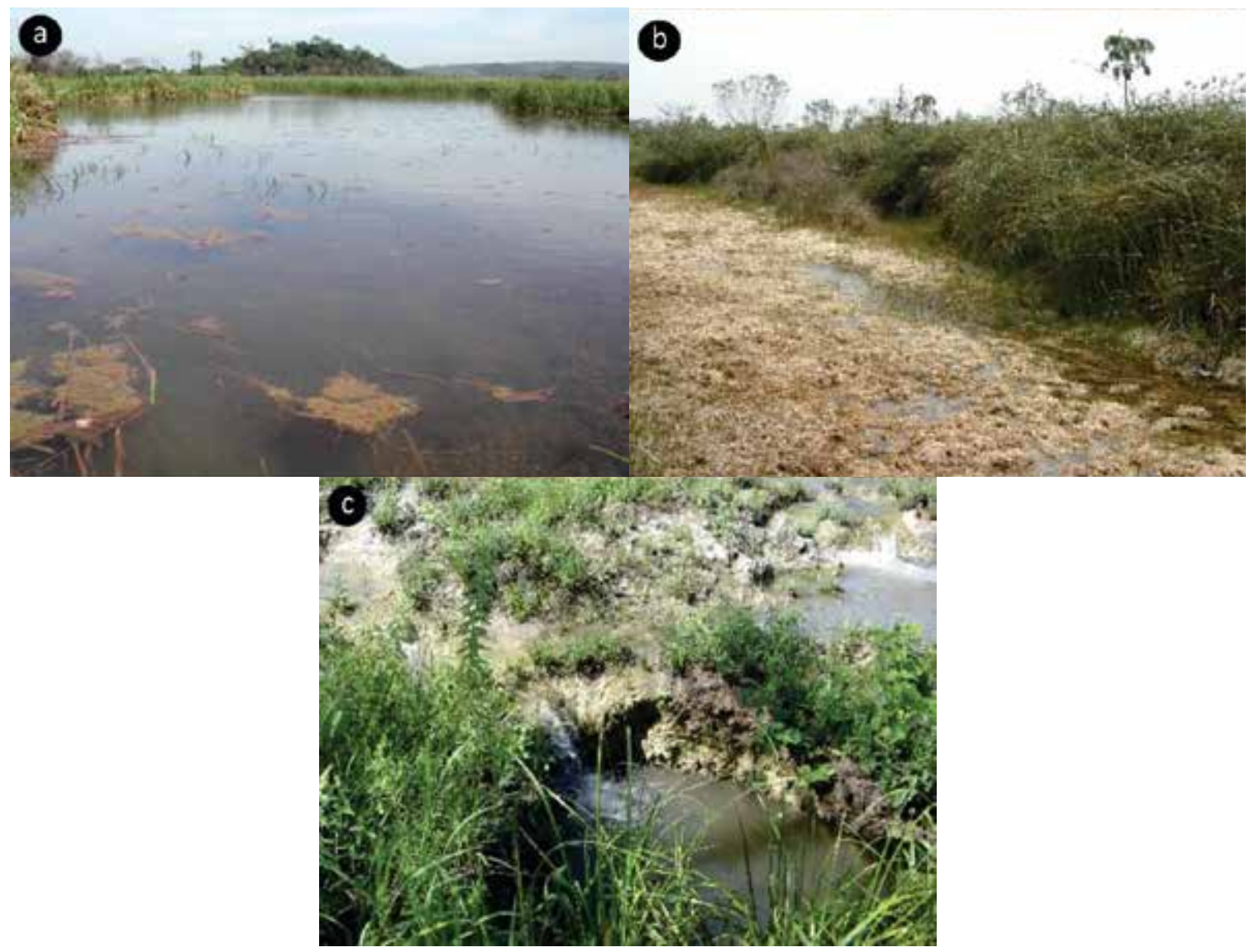


FIGURA 6: Ambientes aquáticos na bacia do rio Perdido: a. Sumidouro; b. Calha principal encaixada entre paredões rochosos, com densa mata ciliar; c. Cachoeira e poção; d. Margens com bambus, no médio curso; e. Córrego "Bambuzal" no período de chuva; f. Cachoeiras no córrego Tombador.

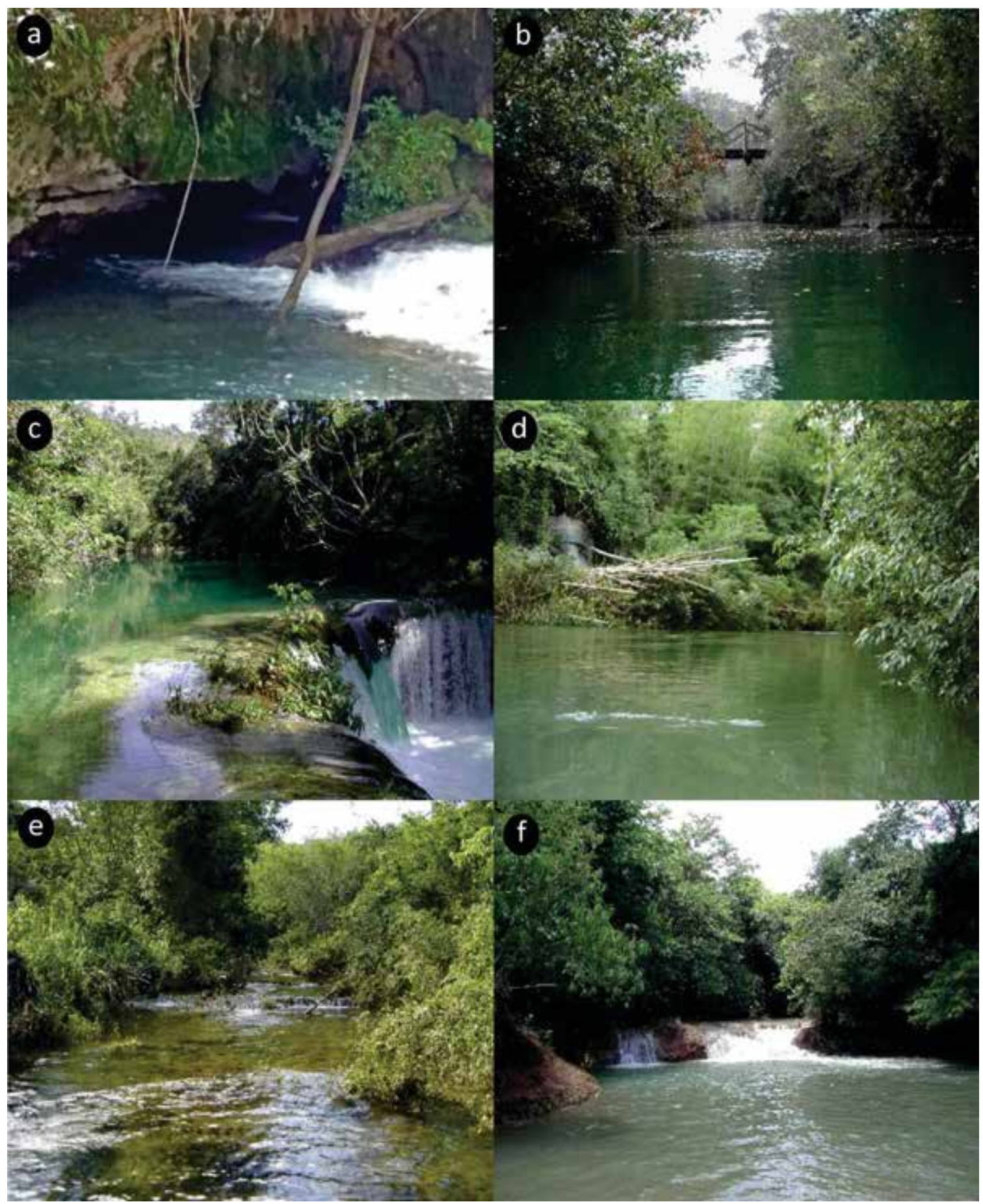


Bacia do rio Formoso. Ao contrário do que ocorre nos rios Salobra e Perdido, as nascentes do rio Formoso e de seus afluentes, córregos Taquaral e Formosinho, encontram-se protegidas dentro do PNSB, em seu extremo leste. Apresenta fluxo temporário e só se torna perene fora da UC, onde é abastecido por águas subterrâneas drenadas a partir do parque (ICMBIO, 2013b). As drenagens apresentam floresta ripária bem preservada e muitos trechos intermitentes, que secam ou permanecem com um volume bem reduzido de água na estiagem, o que favorece a formação de grandes tufas, notadamente onde os desníveis são mais acentuados (Figura 7). As águas são cristalinas, com espessos depósitos folhosos e substrato predominantemente rochoso, com seixos, matacões e lajedos.

\section{Amostragem e tratamento de dados}

Os dados aqui apresentados são provenientes das campanhas da Avaliação Ecológica Rápida (AER), realizadas para obter dados para compor o Plano de Manejo da UC, que ocorreram em duas etapas: a primeira de 30/08/2005 a 10/09/2005 e a segunda de 08 a 20/12/2005. As coletas foram feitas em cinco sítios amostrais das bacias dos rios Salobra e Perdido: Rancho Branco e Remanso, no setor norte, e Laudejá, Harmonia e Campo Verde, no setor sul (Figura 1). Foram realizadas coletas em 27 pontos (Tabela 1), distribuídos prioritariamente dentro da área protegida pelo PNSB, incluindo rios, riachos intermitentes ou perenes, lagoas, banhado e poços interligados ao sistema de águas subterrâneas, sempre conforme a possibilidade de acesso, considerando que as estradas dentro do PNSB são muito precárias.

FIGURA 7: Ambientes aquáticos na bacia do rio Formoso: a. Córrego Formosinho, floresta ripária preservada; b. Córrego Formosinho, substrato com folhiço e seixos; c. Córrego Taquaral, cachoeira de tufas na estação chuvosa; d. Córrego Taquaral, corredeira e poção, em trecho com floresta ripária preservada.

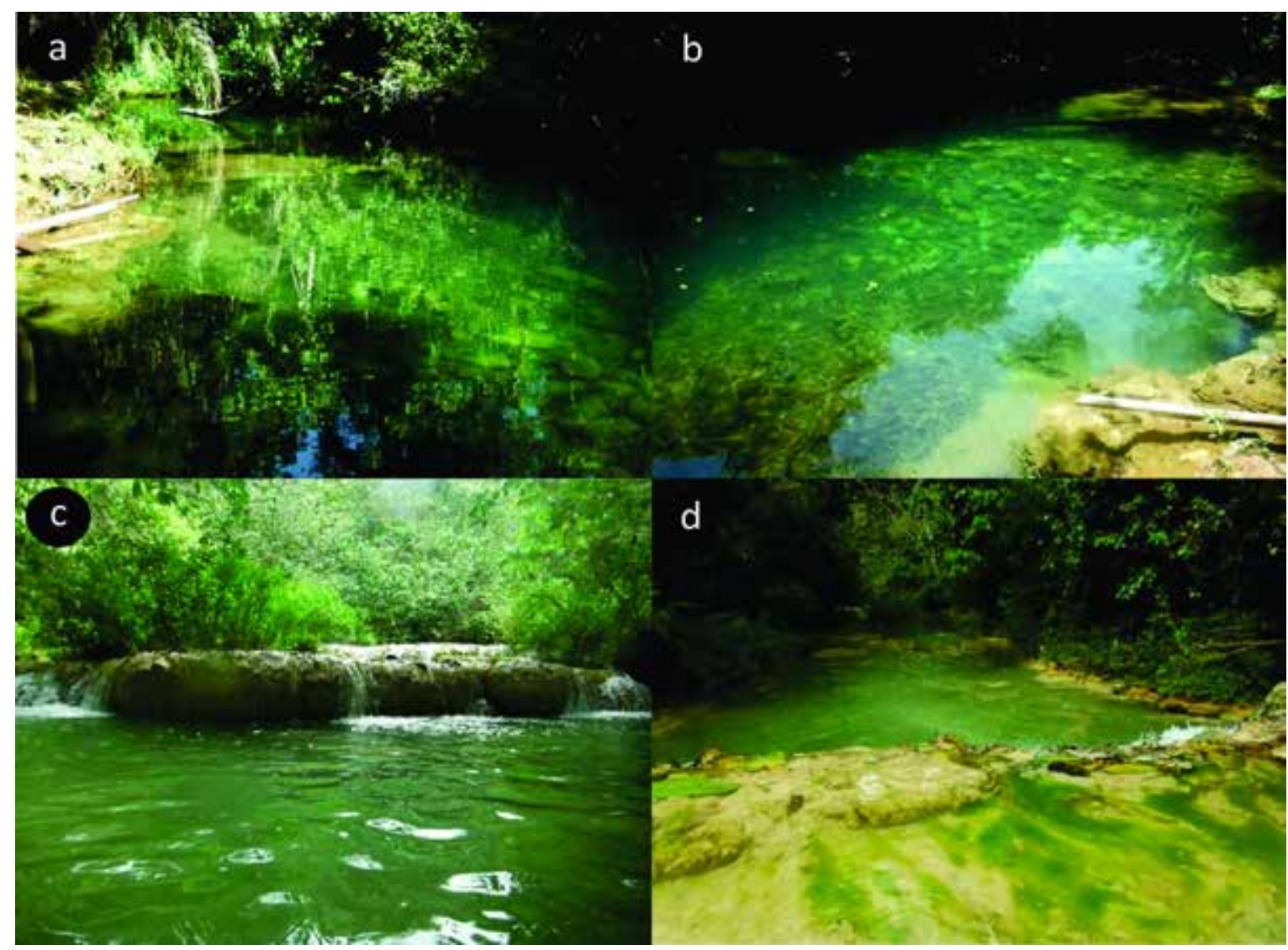


As coletas foram feitas com redes de arrasto, de emalhe e pesca elétrica, aplicadas conforme a viabilidade local. Os arrastos foram efetuados em praias arenosas e em margens de lagoas, com rede tipo picaré de $8,0 \mathrm{~m}$ de comprimento e malha $2,5 \mathrm{~mm}$. As redes de emalhe foram armadas ao final do dia nos pontos com profundidade superior a $1,5 \mathrm{~m}$ e recolhidas nas primeiras horas da manhã seguinte. A eletropesca foi utilizada em trechos com profundidade inferior a $1 \mathrm{~m}$, delimitando-se um segmento com cerca de $100 \mathrm{~m}$ de comprimento com redes de bloqueio com malha de $5 \mathrm{~mm}$, onde foram aplicados os eletrodos, conforme Uieda e Castro (1999). Durante a segunda campanha não foi possível usar a eletropesca na maioria dos pontos da primeira, devido ao maior volume e profundidade da água e, em alguns casos, por falta de acesso ao local. Assim, optou-se pela inclusão de novos pontos de coleta, dentro da mesma drenagem, a fim de aproveitar ambientes intermitentes que estavam secos na campanha anterior. No total, onze pontos foram amostrados nas duas campanhas, cinco na campanha 1 e onze na campanha 2 (Tabela 1 ).

Os exemplares coletados foram anestesiados com eugenol, fixados em formalina $10 \% \mathrm{e}$, posteriormente, lavados e transferidos para álcool $70 \%$. A identificação seguiu Britski et al., $(1999 ; 2007)$ e consulta a especialistas. As coletas foram realizadas sob licença de pesquisa do ICMBIO (processo no 22892-1) e o material coletado está depositado na Coleção Zoológica da Universidade Federal de Mato Grosso do Sul (ZUFMS) (cf. Tabela 2). Todas as fotos pertencem aos acervos particulares dos autores.

TABELA 1: Descrição geral dos pontos de amostragem de ictiofauna durante as campanhas da Avaliação Ecológica Rápida - Parque Nacional da Serra da Bodoquena. Sítios: I. Rancho Branco, II. Remanso, III. Laudejá, IV. Harmonia, V. Campo Verde. C1-C2 indica a campanha em que o ponto foi amostrado; L máx. = Largura máxima; P máx. $=$ Profundidade máxima.

\begin{tabular}{|c|c|c|c|c|c|c|c|c|c|}
\hline Sítio & Ponto & $\mathrm{C} 1-\mathrm{C} 2$ & Drenagem & Ambiente & $\begin{array}{c}\text { Substrato I } \\
\text { predominante }\end{array}$ & $\begin{array}{l}\text { L máx. } \\
\text { (m) }\end{array}$ & $\begin{array}{l}\text { P máx. } \\
\text { (m) }\end{array}$ & Coordenadas & $\begin{array}{l}\text { Alterações } \\
\text { ambientais }\end{array}$ \\
\hline I & 1 & $1-2$ & $\begin{array}{l}\text { Córrego } \\
\text { Salobrinha }\end{array}$ & $\begin{array}{l}\text { Corredeiras, poções e pequenas } \\
\text { quedas. Água límpida. Floresta } \\
\text { ripária preservada. }\end{array}$ & $\begin{array}{l}\text { Laje, matacão, } \\
\text { seixos. }\end{array}$ & 15 & 1,5 & $\begin{array}{l}20^{\circ} 41^{\prime} 08^{\prime \prime} \mathrm{S} \\
56^{\circ} 46^{\prime} 59^{\prime \prime} \mathrm{W}\end{array}$ & \\
\hline I & 2 & $1-2$ & $\begin{array}{l}\text { Córrego } \\
\text { Salobrinha }\end{array}$ & $\begin{array}{l}\text { Corredeiras e remansos. Água } \\
\text { límpida. Floresta ripária preservada. }\end{array}$ & $\begin{array}{l}\text { Laje, matacão, } \\
\text { seixos. }\end{array}$ & 7 & 1,0 & $\begin{array}{l}20^{\circ} 40^{\prime} 58^{\prime \prime} \mathrm{S} \\
56^{\circ} 47^{\prime} 09^{\prime \prime} \mathrm{W}\end{array}$ & \\
\hline I & 3 & 1 & Rio Salobra & $\begin{array}{l}\text { Água límpida. Floresta ripária, } \\
\text { bambu e pastagem. }\end{array}$ & $\begin{array}{l}\text { Seixos, areia e } \\
\text { silte. }\end{array}$ & 20 & 1,5 & $\begin{array}{l}20^{\circ} 40^{\prime} 09 ” \mathrm{~S} \\
56^{\circ} 45^{\prime} 36^{\prime \prime} \mathrm{W}\end{array}$ & Pasto e bambu. \\
\hline I & 4 & $1-2$ & $\begin{array}{l}\text { Córrego } \\
\text { Salobrinha }\end{array}$ & $\begin{array}{l}\text { Trecho lêntico entre duas pequenas } \\
\text { cachoeiras. Água límpida. Floresta } \\
\text { ripária, bambu e pastagem. }\end{array}$ & $\begin{array}{l}\text { Seixos, com } \\
\text { bancos de folhiço } \\
\text { em remansos. }\end{array}$ & 20 & 1,1 & $\begin{array}{l}20^{\circ} 41^{\prime} 05^{\prime \prime} \mathrm{S} \\
56^{\circ} 46^{\prime} 42^{\prime \prime} \mathrm{W}\end{array}$ & $\begin{array}{l}\text { Travessia de } \\
\text { veículo e gado. } \\
\text { Pasto e bambu. }\end{array}$ \\
\hline I & 17 & 2 & $\begin{array}{l}\text { Córrego } \\
\text { Santa Maria }\end{array}$ & $\begin{array}{l}\text { Poções e cachoeiras. Água límpida. } \\
\text { Floresta ripária preservada. }\end{array}$ & $\begin{array}{l}\text { Laje, matacões e } \\
\text { seixos. Depósito } \\
\text { de areia nos } \\
\text { remansos. }\end{array}$ & 15 & 1,5 & $\begin{array}{l}20^{\circ} 40^{\prime} 59^{\prime \prime} \mathrm{S} \\
56^{\circ} 47^{\prime} 08^{\prime \prime} \mathrm{W}\end{array}$ & \\
\hline II & 5 & $1-21$ & Rio Salobra & $\begin{array}{l}\text { Fluxo laminar. Água límpida. } \\
\text { Margeado à direita por paredão } \\
\text { rochoso com bromélias e musgos. } \\
\text { Mata fragmentada na margem } \\
\text { esquerda. }\end{array}$ & $\begin{array}{l}\text { Lajes extensas, } \\
\text { seixos, depósitos } \\
\text { ocasionais de } \\
\text { areia. }\end{array}$ & 30 & 1,1 & $\begin{array}{l}20^{\circ} 46^{\prime} 47^{\prime \prime} \mathrm{S} \\
56^{\circ} 44^{\prime} 27^{\prime \prime} \mathrm{W}\end{array}$ & \\
\hline II & 6 & $1-2$ & Rio Salobra 1 & $\begin{array}{l}\text { Corredeiras e poções. Água límpida. } \\
\text { Arbustos à esquerda e paredão } \\
\text { rochoso à direita. Manchas de Chara } \\
\text { no fundo, sarã nas rochas e tufas no } \\
\text { leito. }\end{array}$ & $\begin{array}{l}\text { Tufas transversais } \\
\text { ao leito, seixos, } \\
\text { depósitos de areia. }\end{array}$ & 30 & 1,3 & $\begin{array}{l}20^{\circ} 46^{\prime} 52^{\prime \prime} \mathrm{S} \\
56^{\circ} 44^{\prime} 26^{\prime \prime} \mathrm{W}\end{array}$ & \\
\hline
\end{tabular}




\begin{tabular}{|c|c|c|c|c|c|c|c|c|c|}
\hline Sítio & Ponto & $\mathrm{C} 1-\mathrm{C} 2$ & 2 Drenagem & Ambiente & $\begin{array}{c}\begin{array}{c}\text { Substrato } \\
\text { predominante }\end{array} \\
\end{array}$ & $\begin{array}{c}\text { L máx. } \\
(\mathrm{m})\end{array}$ & $\begin{array}{l}\text { P máx. } \\
\text { (m) }\end{array}$ & Coordenadas & $\begin{array}{c}\text { Alterações } \\
\text { ambientais }\end{array}$ \\
\hline II & 7 & 1 & $\begin{array}{l}\text { Córrego } \\
\text { sem nome }\end{array}$ & $\begin{array}{l}\text { Intermitente, com pequenos poços } \\
\text { formados por tufas, pouca água. } \\
\text { Água límpida. Floresta ripária } \\
\text { fechada. }\end{array}$ & $\begin{array}{l}\text { Lajes e matacões. } \\
\text { Areia em trechos } \\
\text { calmos. }\end{array}$ & 3 & 0,3 & $\begin{array}{l}20^{\circ} 46^{\prime} 29^{\prime \prime} \mathrm{S} \\
56^{\circ} 44^{\prime} 15^{\prime \prime} \mathrm{W}\end{array}$ & \\
\hline II & 8 & 1 & $\begin{array}{l}\text { Córrego } \\
\text { sem nome }\end{array}$ & $\begin{array}{l}\text { Intermitente, vale escavado, quedas } \\
\text { grandes e tufas gigantes. Poções } \\
\text { com maior volume de água, límpida. } \\
\text { Floresta ripária fechada. }\end{array}$ & $\begin{array}{l}\text { Lajes e matacões. } \\
\text { Areia e folhiço } \\
\text { em trechos } \\
\text { calmos. }\end{array}$ & 5 & 0,8 & $\begin{array}{l}20^{\circ} 46^{\prime} 52^{\prime \prime} \mathrm{S} \\
56^{\circ} 44^{\prime} 26^{\prime \prime} \mathrm{W}\end{array}$ & \\
\hline II & 9 & 1 & $\begin{array}{l}\text { Córrego } \\
\text { sem nome }\end{array}$ & $\begin{array}{l}\text { Intermitente. Pequenos poços } \\
\text { formados por tufas, com pouca } \\
\text { água, que é límpida. Floresta ripária } \\
\text { fechada. }\end{array}$ & $\begin{array}{l}\text { Lajes e matacões. } \\
\text { Areia e folhiço } \\
\text { em trechos } \\
\text { calmos. }\end{array}$ & 5 & 0,5 & $\begin{array}{l}20^{\circ} 46^{\prime} 52^{\prime \prime} \mathrm{S} \\
56^{\circ} 44^{\prime} 26^{\prime \prime} \mathrm{W}\end{array}$ & \\
\hline III & 10 & $1-2$ & $\begin{array}{l}\text { Banhado } \\
\text { do Perdido }\end{array}$ & $\begin{array}{l}\text { Canais estreitos e rasos, escavados } \\
\text { na estiagem. Correnteza fraca. Água } \\
\text { límpida. Pasto sujo, bancos de capim- } \\
\text { navalha e de Bacopa. }\end{array}$ & $\begin{array}{l}\text { Depósitos } \\
\text { espessos de silte e } \\
\text { argila }\end{array}$ & 1 & 0,5 & $\begin{array}{l}21^{\circ} 05^{\prime} 52^{\prime \prime} \mathrm{S} \\
56^{\circ} 48^{\prime} 26^{\prime \prime} \mathrm{W}\end{array}$ & $\begin{array}{l}\text { Pasto, pisoteio } \\
\text { pelo gado (a } \\
\text { montante do } \\
\text { ingresso no } \\
\text { PNSB). }\end{array}$ \\
\hline III & 11 & $1-2$ & Rio Perdido & $\begin{array}{l}\text { Corredeiras, poções e trechos com } \\
\text { fluxo laminar, na ponte velha da } \\
\text { Fazenda São Pascoal. Água clara. } \\
\text { Faixa estreita de arvoretas e arbustos, } \\
\text { seguida por pastagem. }\end{array}$ & $\begin{array}{l}\text { Grandes lajes de } \\
\text { calcário, cascalho, } \\
\text { areia e silte nos } \\
\text { remansos. }\end{array}$ & 10 & 1,5 & $\begin{array}{l}21^{\circ} 05^{\prime} 42^{\prime \prime} \mathrm{S} \\
56^{\circ} 48^{\prime} 26^{\prime \prime} \mathrm{W}\end{array}$ & $\begin{array}{l}\text { Trânsito de } \\
\text { gado. Pasto. }\end{array}$ \\
\hline III & 12 & $1-2$ & $\begin{array}{l}\text { Banhado } \\
\text { do Perdido }\end{array}$ & $\begin{array}{l}\text { Sequência de ambientes interligados: } \\
\text { canal em meio ao capim-navalha, } \\
\text { com pequenas quedas d'água; poço } \\
\text { fundo no meio de lagoa seca; lagoa. } \\
\text { Água límpida e corrente. Capim- } \\
\text { navalha e herbáceas, algas verdes; } \\
\text { bancos de Chara e macrófitas } \\
\text { submersas na lagoa. }\end{array}$ & Silte e argila. & $\begin{array}{l}\text { Poço } \\
-0,5 \\
\text { Lagoa } \\
-50 \\
\end{array}$ & $\begin{array}{l}1,5 \\
2\end{array}$ & $\begin{array}{l}21^{\circ} 07^{\prime} 18^{\prime \prime} \mathrm{S} \\
56^{\circ} 46^{\prime} 33^{\prime \prime} \mathrm{W}\end{array}$ & $\begin{array}{l}\text { Pisoteio por } \\
\text { gado. Pastagem. }\end{array}$ \\
\hline III & 15 & $1-2$ & $\begin{array}{l}\text { Poço e } \\
\text { lagoa }\end{array}$ & $\begin{array}{l}\text { Poço ligado ao sistema subterrâneo } \\
\text { na sede da Fazenda Laudejá, vizinha } \\
\text { ao PNSB. Macrófitas e gramíneas. }\end{array}$ & $\begin{array}{l}\text { Lagoa com fundo } \\
\text { argiloso. }\end{array}$ & 10 & 1,5 & $\begin{array}{l}21^{\circ} 08^{\prime} 44^{\prime \prime} \mathrm{S} \\
56^{\circ} 47^{\prime} 30^{\prime \prime} \mathrm{W}\end{array}$ & \\
\hline III & 16 & 1 & $\begin{array}{l}\text { Banhado } \\
\text { do Perdido }\end{array}$ & $\begin{array}{l}\text { Lagoa rasa, circundada por brejo. } \\
\text { Capim-navalha queimado na } \\
\text { margem, Bacopa e Nymphaea no } \\
\text { alagado. }\end{array}$ & $\begin{array}{l}\text { Argiloso, com } \\
\text { muito material } \\
\text { orgânico. }\end{array}$ & 5 & 0,5 & $\begin{array}{l}21^{\circ} 07^{\prime} 03^{\prime \prime S} \\
56^{\circ} 46^{\prime} 35^{\prime \prime} \mathrm{W}\end{array}$ & $\begin{array}{l}\text { Vegetação } \\
\text { queimada (a } \\
\text { montante do } \\
\text { ingresso no } \\
\text { PNSB). } \\
\end{array}$ \\
\hline IV & 13 & $1-2$ & $\begin{array}{l}\text { Rio } \\
\text { Perdido }\end{array}$ & $\begin{array}{l}\text { Trecho encaixado entre paredões } \\
\text { íngremes, cobertos por mata ciliar } \\
\text { bem preservada. Água transparente, } \\
\text { baixa velocidade, muito profundo. }\end{array}$ & $\begin{array}{l}\text { Blocos do fundo } \\
\text { recobertos por } \\
\text { camada argilosa, } \\
\text { de cor clara. }\end{array}$ & 80 & $\begin{array}{c}10 \\
\text { (estimado) }\end{array}$ & $\begin{array}{l}21^{\circ} 17^{\prime} 09^{\prime \prime S} \\
56^{\circ} 41^{\prime} 47^{\prime \prime} \mathrm{W}\end{array}$ & \\
\hline IV & 14 & $1-2$ & $\begin{array}{l}\text { Poço e } \\
\text { surgência }\end{array}$ & $\begin{array}{l}\text { Poço ligado a surgência, na antiga } \\
\text { sede da Fazenda Harmonia, } \\
\text { formando regato sobre lajedo, que } \\
\text { deságua em uma lagoa. Bacopa no } \\
\text { lajedo e macrófitas na lagoa. }\end{array}$ & $\begin{array}{l}\text { Lajedo, espessa } \\
\text { camada de lama } \\
\text { na lagoa. }\end{array}$ & 6 & 0,7 & $\begin{array}{l}21^{\circ} 12^{\prime} 54^{\prime \prime} \mathrm{S} \\
56^{\circ} 45^{\prime} 58^{\prime \prime} \mathrm{W}\end{array}$ & $\begin{array}{l}\text { Moradias } \\
\text { abandonadas }\end{array}$ \\
\hline IV & 18 & 2 & $\begin{array}{l}\text { Córrego } \\
\text { "Bambuzal" }\end{array}$ & $\begin{array}{l}\text { Temporário, seco na estiagem. } \\
\text { Troncos de bambu sobre o leito. } \\
\text { Margem com bambu, arbustos e } \\
\text { capim. }\end{array}$ & $\begin{array}{l}\text { Rochoso, } \\
\text { recoberto com } \\
\text { folhiço denso. }\end{array}$ & 4 & 2 & $\begin{array}{l}21^{\circ} 16^{\prime} 13^{\prime \prime} \mathrm{S} \\
56^{\circ} 43^{\prime} 10^{\prime \prime} \mathrm{W}\end{array}$ & $\begin{array}{l}\text { Bambu e restos } \\
\text { de pasto. }\end{array}$ \\
\hline
\end{tabular}




\begin{tabular}{|c|c|c|c|c|c|c|c|c|c|}
\hline Sítio & Ponto C & $\mathrm{C1}-\mathrm{C} 2$ & 2 Drenagem & Ambiente & $\begin{array}{c}\text { Substrato } \\
\text { predominante }\end{array}$ & $\begin{array}{l}\text { L máx. } \\
(\mathrm{m})\end{array}$ & $\begin{array}{l}\text { P máx. } \\
(\mathrm{m})\end{array}$ & Coordenadas & $\begin{array}{l}\text { Alterações } \\
\text { ambientais }\end{array}$ \\
\hline IV & 19 & 2 & $\begin{array}{l}\text { Córrego } \\
\text { "Bambuzal' }\end{array}$ & $\begin{array}{l}\text { Encravado em ravina profunda (4 } \\
\mathrm{m}) \text {, corrente mais lenta, represada } \\
\text { " por bambus. Vegetação arbórea na } \\
\text { margem direita. }\end{array}$ & $\begin{array}{l}\text { Argilo-arenoso, } \\
\text { com muito } \\
\text { folhiço e troncos } \\
\text { de bambu. }\end{array}$ & 3 & 0,5 & $\begin{array}{l}21^{\circ} 16^{\prime} 50^{\prime \prime} \mathrm{S} \\
56^{\circ} 42^{\prime} 46^{\prime \prime} \mathrm{W}\end{array}$ & Bambu. \\
\hline IV & 20 & 2 & $\begin{array}{l}\text { Córrego } \\
\text { "Bambuzal' }\end{array}$ & $\begin{array}{l}\text { A jusante de P19, com mais fluxo } \\
\text { "de água, corredeiras, poços e queda. } \\
\text { Bambu, arbustos e trepadeiras. }\end{array}$ & Seixos. & 8 & 2,5 & $\begin{array}{l}21^{\circ} 17^{\prime} 07^{\prime \prime S} \\
56^{\circ} 42^{\prime} 10^{\prime \prime} \mathrm{W}\end{array}$ & Bambu. \\
\hline IV & 21 & 2 & $\begin{array}{l}\text { Córrego } \\
\text { "Bambuzal' }\end{array}$ & $\begin{array}{l}\text { A jusante do P20, com trechos de } \\
\text { "fluxo laminar intercalados a tufas. }\end{array}$ & $\begin{array}{l}\text { Blocos rochosos } \\
\text { e seixos. }\end{array}$ & 8 & 0,7 & $\begin{array}{l}21^{\circ} 17^{\prime} 19^{\prime \prime} \mathrm{S} \\
56^{\circ} 41^{\prime} 54^{\prime \prime} \mathrm{W}\end{array}$ & Bambu. \\
\hline IV & 22 & 2 & Açude & $\begin{array}{l}\text { Açude próximo à estrada para o rio } \\
\text { Perdido. Muita gramínea no fundo. }\end{array}$ & Argiloso. & 50 & 0,8 & $\begin{array}{l}21^{\circ} 15^{\prime} 19^{\prime \prime} \mathrm{S} \\
56^{\circ} 43^{\prime} 29^{\prime \prime} \mathrm{W}\end{array}$ & $\begin{array}{l}\text { Açude em } \\
\text { fazenda, usado } \\
\text { pelo gado. } \\
\end{array}$ \\
\hline IV & 23 & 2 & $\begin{array}{l}\text { Lagoa } \\
\text { marginal ao } \\
\text { rio Perdido }\end{array}$ & $\begin{array}{l}\text { Lagoa marginal, seca na estiagem. } \\
\text { Ligada ao rio por um canal, } 400 \mathrm{~m} \\
\text { a jusante da ponte. Água límpida. } \\
\text { Muitas folhas na superfície. Floresta } \\
\text { ripária preservada. }\end{array}$ & $\begin{array}{l}\text { Argiloso, com } \\
\text { muito folhiço e } \\
\text { blocos de rocha } \\
\text { expostos. }\end{array}$ & 80 & 2 & $\begin{array}{l}21^{\circ} 17^{\prime} 14^{\prime \prime S} \\
56^{\circ} 41^{\prime} 46^{\prime \prime} \mathrm{W}\end{array}$ & \\
\hline IV & 24 & 2 & $\begin{array}{l}\text { Foz do } \\
\text { Córrego } \\
\text { "Bambuzal' }\end{array}$ & $\begin{array}{l}\text { Trecho lêntico, junção com rio } \\
\text { Perdido, após uma sucessão de } \\
\text { „quedas e cachoeiras. Floresta ripária } \\
\text { preservada. }\end{array}$ & $\begin{array}{l}\text { Blocos rochosos } \\
\text { e seixos, troncos } \\
\text { de madeira da } \\
\text { ponte. }\end{array}$ & 30 & 1,5 & $\begin{array}{l}21^{\circ} 17^{\prime} 22^{\prime \prime S} \\
56^{\circ} 41^{\prime} 42^{\prime \prime W}\end{array}$ & \\
\hline $\mathrm{V}$ & 25 & 2 & $\begin{array}{l}\text { Córrego } \\
\text { Tombador }\end{array}$ & $\begin{array}{l}\text { Próximo à foz, com quedas e } \\
\text { cachoeiras. Água turva. Na foz, água } \\
\text { represada pelo rio Perdido. Barranco } \\
\text { alto }(8 \mathrm{~m})\end{array}$ & $\begin{array}{l}\text { Rochoso, com } \\
\text { tufas, areia } \\
\text { e folhiço em } \\
\text { trechos mais } \\
\text { fundos. }\end{array}$ & 20 & 1,5 & $\begin{array}{l}21^{\circ} 23^{\prime} 52^{\prime \prime} \mathrm{S} \\
56^{\circ} 45^{\prime} 07^{\prime \prime} \mathrm{W}\end{array}$ & Assoreamento. \\
\hline $\mathrm{V}$ & 26 & 2 & $\begin{array}{l}\text { Rio } \\
\text { Perdido }\end{array}$ & $\begin{array}{l}\text { Pequena praia. Água turva. Margem } \\
\text { com pastagem. }\end{array}$ & $\begin{array}{l}\text { Arenoso- } \\
\text { argiloso, seixos } \\
\text { na parte mais } \\
\text { profunda. }\end{array}$ & 10 & 2 & $\begin{array}{l}21^{\circ} 25^{\prime} 35^{\prime \prime} \mathrm{S} \\
56^{\circ} 45^{\prime} 46^{\prime \prime} \mathrm{W}\end{array}$ & $\begin{array}{l}\text { Local de acesso } \\
\text { para gado, com } \\
\text { intenso pisoteio. }\end{array}$ \\
\hline $\mathrm{V}$ & 27 & 2 & $\begin{array}{l}\text { Córrego } \\
\text { sem nome }\end{array}$ & $\begin{array}{l}\text { Muitas tufas pequenas, água corrente, } \\
\text { turva. Floresta ripária e pastagem }\end{array}$ & $\begin{array}{l}\text { Rochoso, areia } \\
\text { nos poções. }\end{array}$ & 3 & 1,1 & $\begin{array}{l}20^{\circ} 26^{\prime} 03^{\prime \prime S} \\
56^{\circ} 47^{\prime} 08^{\prime \prime} \mathrm{W}\end{array}$ & $\begin{array}{l}\text { Pisoteio de gado. } \\
\text { Assoreamento. }\end{array}$ \\
\hline
\end{tabular}

A lista das espécies foi elaborada com os dados obtidos nas duas campanhas da AER, aos quais foram acrescentados os registros de espécies coletadas por Severo-Neto, com redes de arrasto, em uma campanha realizada em fevereiro de 2013 nas cabeceiras dos córregos Taquaral e Formosinho, em fevereiro/2013, como parte do Projeto de Implantação de um Sistema de Monitoramento no PNSB, Mato Grosso do Sul. Dados de Froehlich (2010) e registros de material depositado na coleção ZUFMS, provenientes de outras coletas esporádicas, também auxiliaram na composição.
Com base na lista final, confeccionou-se um diagrama de Venn e estimou-se a similaridade na composição da ictiofauna das bacias dos rios Formoso, Salobra e Perdido, aplicando-se o índice de Jaccard $(J)$.

Alterações ambientais que podem representar possíveis ameaças à conservação do PNSB foram descritas a partir de observações feitas em campo, durante as campanhas da AER, acrescentando-se dados secundários como referência a impactos potenciais (MATO GROSSO DO SUL, 2014). 


\section{Resultados}

\section{Análise dos dados da Avaliação \\ Ecológica Rápida (AER) - 2005}

Nas campanhas da AER foram registradas 40

espécies de peixes (Tabela 2).

TABELA 2: Ictiofauna do Parque Nacional da Serra da Bodoquena, Mato Grosso do Sul, Brasil. Ocorrência das espécies por bacia $($ Sal $=$ Salobra, Per $=$ Perdido, For $=$ Formoso) e nas expedições da Avaliação Ecológica Rápida (AER). Números representam os exemplares-testemunho depositados na coleção ZUFMS. Categorias taxonômicas seguem van der Laan et al. (2020). * Não catalogado. ** Coleção MZUSP.

\begin{tabular}{lccccc}
\hline & Táxon & Sal & Per & For & AER \\
\hline ORDEM MYLIOBATIFORMES & & & & &
\end{tabular}

Família Potamotrygonidae

Potamotrygon falkneri Castex \& Maciel, 1963

$*$

ORDEM CHARACIFORMES

Família Crenuchidae

Characidium sp.

Characidium aff. zebra Eigenmann, 1909

Família Erythrinidae

Hoplias cf. malabaricus (Bloch, 1794)

Família Parodontidae

Parodon nasus Kner, 1859

1102

4699

Leporinus friderici (Bloch, 1794)

Família Curimatidae

Steindachnerina brevipinna (Eigenmann \& Eigenmann, 1889)

Steindachnerina nigrotaenia (Boulenger, 1902)

0913

4547

Família Prochilodontidae

Prochilodus lineatus (Valenciennes, 1836)

5051

Família Bryconidae

Brycon hilarii (Valenciennes, 1850)

4549

Salminus brasiliensis (Cuvier, 1816)

3350

4592

Acestrorhynchus pantaneiro Menezes, 1992

Família Characidae

Aphyocharax dentatus Eigenmann \& Kennedy, 1903

4616

Astyanax abramis (Jenyns, 1842)

4079

Astyanax lacustris (Lütken, 1875)

Astyanax lineatus (Perugia, 1891)

4565

0910

Astyanax sp.1

Astyanax sp.2

Brachychalcinus retrospina Boulenger, 1892

Bryconamericus exodon Eigenmann, 1907

Bryconops melanurus (Bloch, 1794)
$\mathrm{X}$

$$
5527
$$

2529

3600

$\mathrm{X}$

605

$\begin{array}{ll}3281 & \mathrm{X} \\ & \mathrm{X} \\ & \mathrm{X} \\ & \\ & \mathrm{X} \\ & \mathrm{X} \\ \mathrm{X}\end{array}$

$\mathrm{X}$ 


\begin{tabular}{|c|c|c|c|c|}
\hline Táxon & Sal & Per & For & AER \\
\hline Hemigrammus lunatus Durbin, 1918 & 2665 & & & \\
\hline Hyphessobrycon luetkeni (Boulenger, 1887) & & 2583 & 3602 & $\mathrm{X}$ \\
\hline Jupiaba acanthogaster (Eigenmann, 1911) & 4650 & 2503 & 3283 & $\mathrm{X}$ \\
\hline Moenkhausia bonita Benine, Castro \& Sabino, 2004 & 1516 & & 3603 & $\mathrm{X}$ \\
\hline Moenkhausia forestii Benine, Mariguela \& Oliveira, 2009) & 3338 & & & $\mathrm{X}$ \\
\hline Odontostilbe pequira (Steindachner, 1882) & 1165 & & & $\mathrm{X}$ \\
\hline Oligosarcus perdido Ribeiro, Cavallaro \& Froehlich, 2007 & & 5460 & & $\mathrm{X}$ \\
\hline Poptella paraguayensis (Eigenmann, 1907) & 1450 & & & $\mathrm{X}$ \\
\hline Serrapinnus calliurus (Boulenger, 1900) & 2532 & & & $\mathrm{X}$ \\
\hline Xenurobrycon macropus Ribeiro \& Myers, 1945 & 4193 & & & $\mathrm{X}$ \\
\hline
\end{tabular}

\section{ORDEM SILURIFORMES}

Família Auchenipteridae

Tatia neivai (Ihering, 1930)

Família Heptapteridae

Imparfinis schubarti (Gomes, 1956)

Phenacorhamdia hoehnei (Miranda Ribeiro, 1914)

Pimelodella taenioptera Miranda Ribeiro, 1914

Rhamdia aff. quelen (Quoy \& Gaimard, 1824)

Família Pseudopimelodidae

Pseudopimodelus mangurus (Valenciennes, 1835)

Família Callichthyidae

Corydoras aeneus (Gill, 1858)

Família Trichomycteridae

Trichomycterus dali Rizzato, Costa, Trajano \& Bichuette, 2011** 810520

Trichomycterus sp.

4114

Família Loricariidae

Ancistrus formoso Sabino \& Trajano, 1997

Ancistrus sp.

Farlowella paraguayensis Retzer \& Page, 1997

Hypostomus basilisko Tencatt, Zawadzki \& Froehlich, 2014

Hypostomus perdido Zawadzki, Tencatt \& Froehlich, 2014

Hypostomus froehlichi Zawadzki, Nardi \& Tencatt, 2021

Hypostomus sp. 2

4541

0906

0907

1685

4142

1313

Loricaria luciae Thomas, Rodriguez, Carvallaro, Froehlich \& Castro, 2013

Otocinclus vitattus Regan, 1904

Rineloricaria lanceolata (Günther, 1868)

\section{ORDEM GYMNOTIFORMES}

Família Sternopygidae

Sternopygus macrurus (Bloch \&Schneider, 1801)

4714

Família Apteronotidae

Apteronotus caudimaculosus Santana, 2003

\section{ORDEM SYNBRANCHIFORMES}

Família Synbranchidae

Synbranchus aff. marmoratus Bloch, 1795
5689

1720

0874

1294

3276

1468

$2585 \quad 3604$

$\mathrm{X}$

$\mathrm{X}$

$\mathrm{X}$

$\mathrm{X}$

$3606 \quad \mathrm{X}$

3605

$\mathrm{X}$

2437

1555

X
$\mathrm{X}$

$\mathrm{X}$

$\mathrm{X}$

X

X 


\begin{tabular}{|c|c|c|c|c|}
\hline Táxon & Sal & Per & For & AER \\
\hline \multicolumn{5}{|l|}{ ORDEM CICHLIFORMES } \\
\hline \multicolumn{5}{|l|}{ Família Cichlidae } \\
\hline Australoheros sp. & & 2502 & & $\mathrm{X}$ \\
\hline Bujurquina vittata (Heckel, 1840) & 4505 & & & $\mathrm{X}$ \\
\hline Cichlasoma dimerus (Heckel 1840) & & 2640 & 3598 & \\
\hline Coptodon rendalli (Boulenger, 1897) & & 2508 & & $X$ \\
\hline Crenicichla lepidota Heckel, 1840 & 1454 & 5535 & 3599 & $\mathrm{X}$ \\
\hline Crenicichla vittata Heckel, 1840 & 1307 & & & \\
\hline
\end{tabular}

\section{ORDEM BELONIFORMES}

Família Belonidae

Potamorrhaphis eigenmanni Miranda Ribeiro, 1915

2812

Na bacia do rio Salobra, ocorreram 32 espécies e quatro ordens: Characiformes foi a mais diversa (59,4\% das espécies) e a mais abundante $(72,5 \%$ do total capturado), seguida por Siluriformes $(34,4 \%$ e $27,3 \%)$, Synbranchiformes $(3,1 \%$ e $0,1 \%)$ e Myliobatiformes $(3,1 \%$ e $0,02 \%)$. As três espécies mais abundantes nesta bacia, Astyanax lineatus, Ancistrus sp. e Odontostilbe pequira, representaram $64,1 \%$ das capturas; as demais foram individualmente inferiores a 9\% (Figura 8). Entre as seis espécies representadas por apenas um indivíduo, três são de grande porte: dourado Salminus brasiliensis, piraputanga Brycon hilarii e corimba Prochilodus lineatus. No rio Salobra ocorreu o único registro da arraia Potamotrygon falkneri.
Entre as espécies da lista geral do PNSB, apenas Hypostomus sp.2, registrada no rio Formoso, não foi coletada durante a AER. Cinco táxons recentemente descritos foram capturados nestas campanhas: Hypostomus basilisko (TENCATT et al., 2014), Hypostomus froehlichi (ZAWADZKI et al., 2021), Hypostomus perdido (ZAWADZKI et al., 2014), Loricaria luciae (THOMAS et al., 2013) e Oligosarcus perdido (RIBEIRO et al., 2007).

\section{Composição geral da ictiofauna}

No total foram registradas 60 espécies nas drenagens superficiais do PNSB, distribuídas em sete ordens e 21 famílias (Tabela 2 e Figura 9). Considerando

FIGURA 8: Abundância relativa das principais espécies nas coletas da Avaliação Ecológica Rápida, nas bacias dos rios Salobra e Perdido, PNSB, Brasil. Em colorido, as espécies compartilhadas.

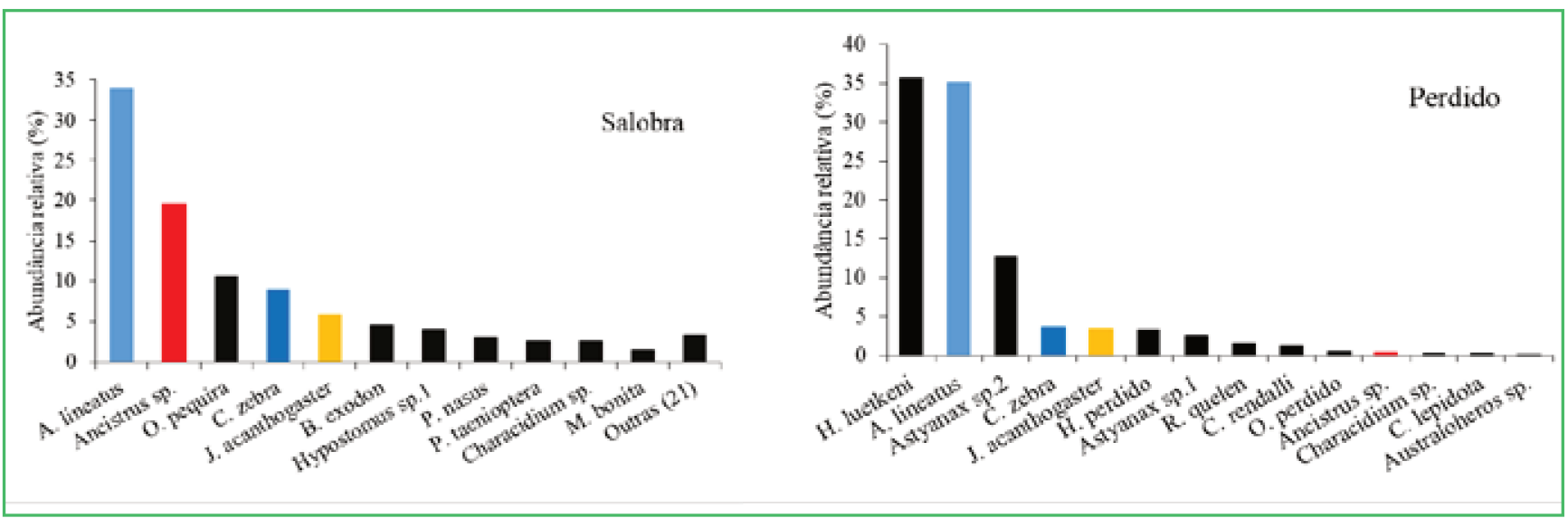


FIGURA 9: Algumas das espécies de peixes registradas nos levantamentos do PNSB: a. Astyanax lineatus; b. Astyanax sp.1; c. Hyphessobrycon luetkeni; d. Oligosarcus perdido; e. Characidium sp.; f. Australoheros sp.

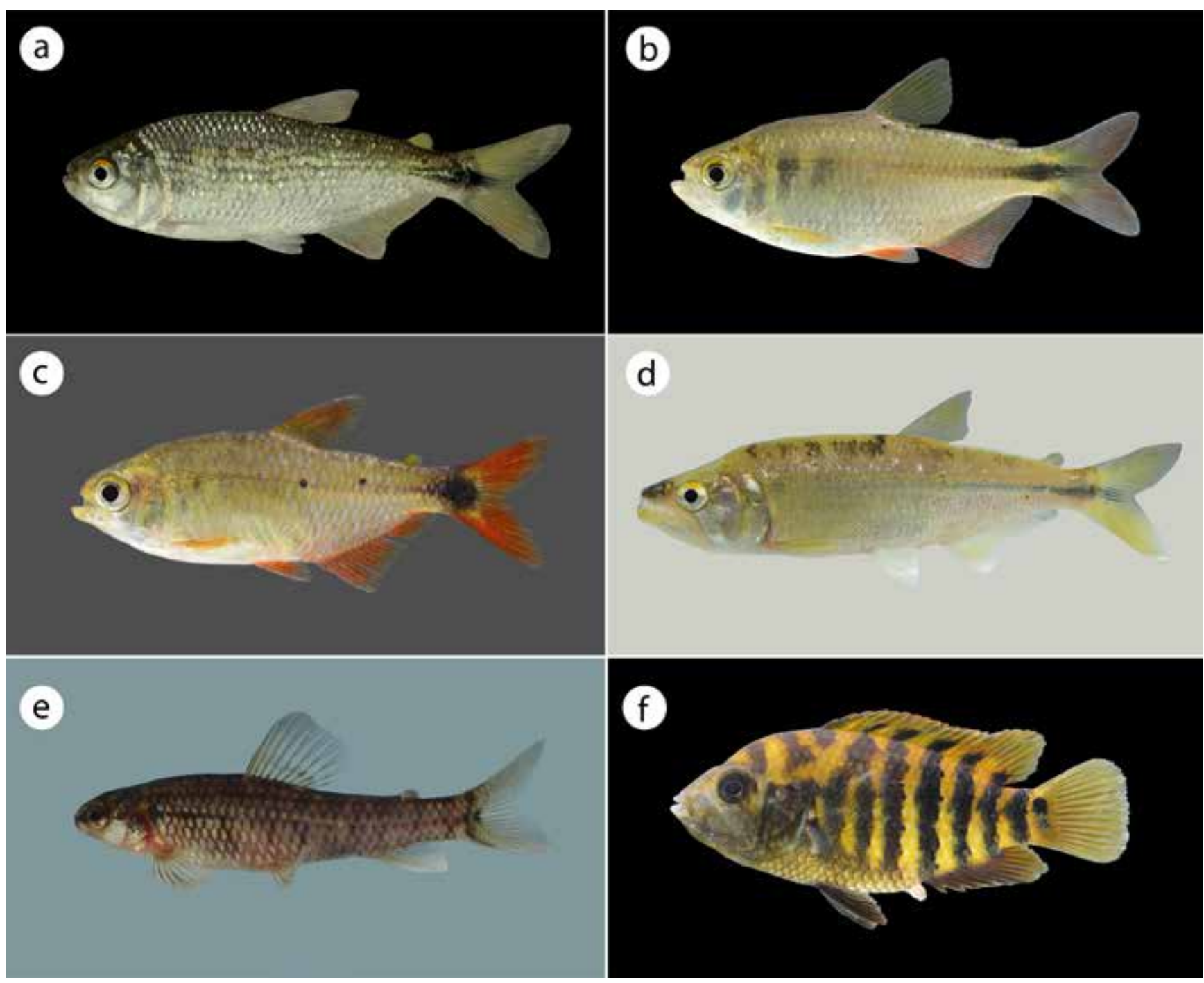

as 40 espécies coletadas durante a AER, os dados complementares somaram $33,3 \%$ do total. As ordens com maior riqueza em espécies foram Characiformes (50\% do total) e Siluriformes $(31,7 \%)$, seguidas por Cichliformes (10\%), Gymnotiformes $(3,3 \%)$ e Synbranchiformes, Beloniformes e Myliobatiformes (1,7\% cada) (Figura 10).

Characiformes e Siluriformes foram os grupos mais ricos em espécies nos rios Salobra e Formoso, enquanto Cichliformes foi o mais diverso na bacia do Perdido. Myliobatiformes, Beloniformes, Synbranchiformes e
Gymnotiformes só ocorreram na bacia do rio Salobra (Figura 11). As famílias mais diversas foram Characidae, Loricariidae, Cichlidae e Heptapteridae. As demais foram representadas por apenas duas ou uma espécie.

A bacia do rio Salobra abriga, além da maior riqueza (49 spp.), o maior número de espécies exclusivas (38 spp.) (Figura 12). Na bacia do rio Perdido a riqueza foi menor (15 spp.), com seis espécies exclusivas. Já nas cabeceiras da bacia do rio Formoso registramos 15 espécies, três exclusivas. 
FIGURA 10: Número total de espécies e de famílias de peixes registradas no PNSB conforme a ordem taxonômica.

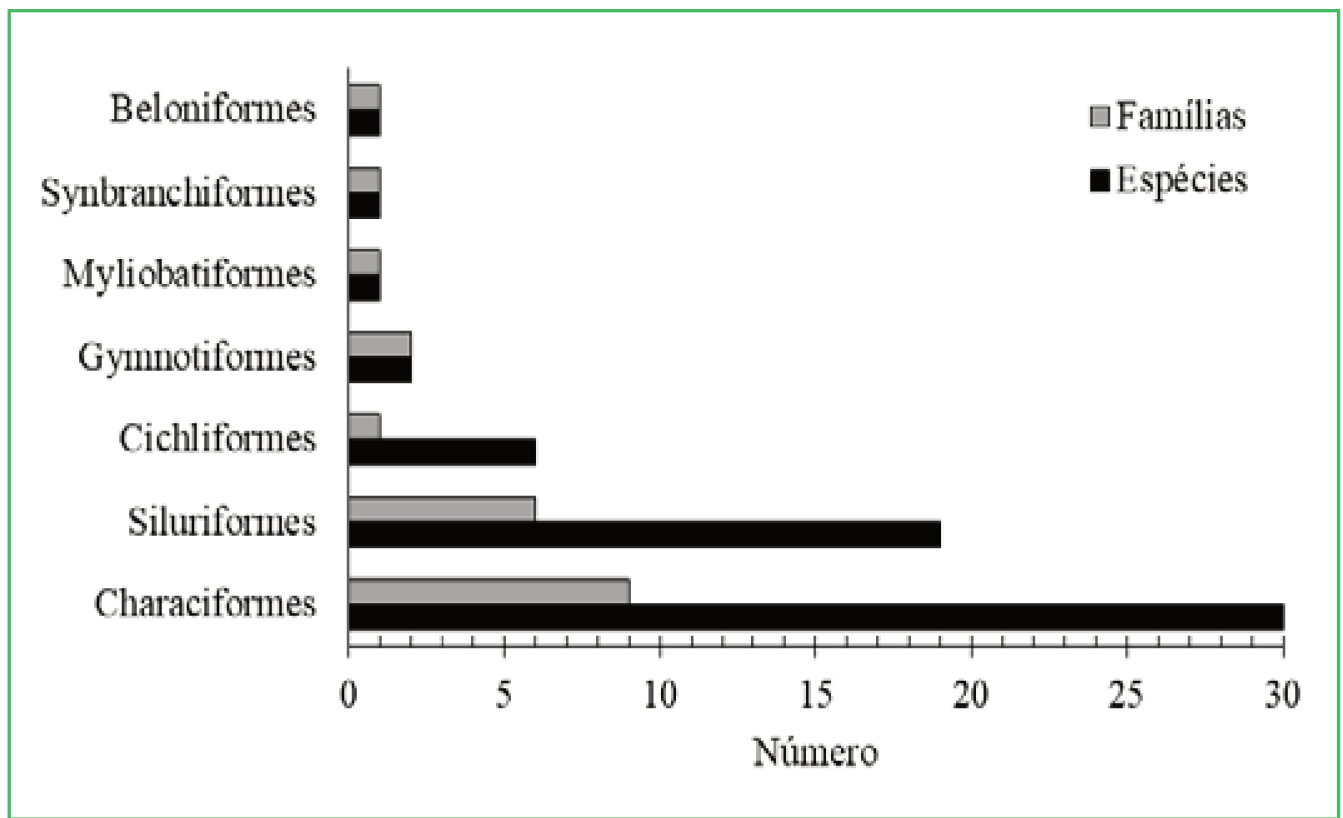

FIGURA 11: Riqueza de espécies em cada ordem, nas bacias dos rios Formoso, Perdido e Salobra, PNSB, Brasil.

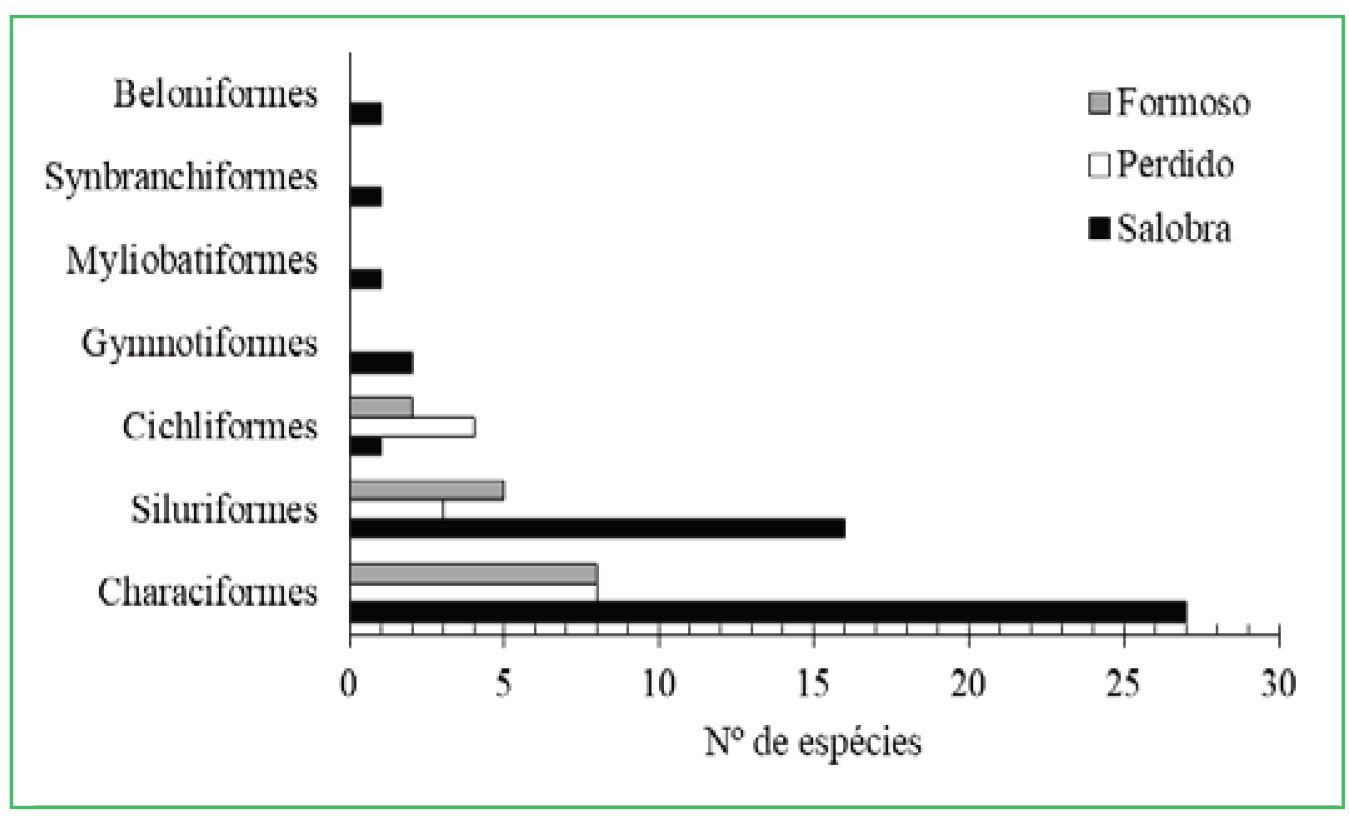


FIGURA 12: Diagrama de Venn, com a distribuição das espécies nas bacias dos rios Salobra (azul), Perdido (alaranjado) e Formoso (verde).

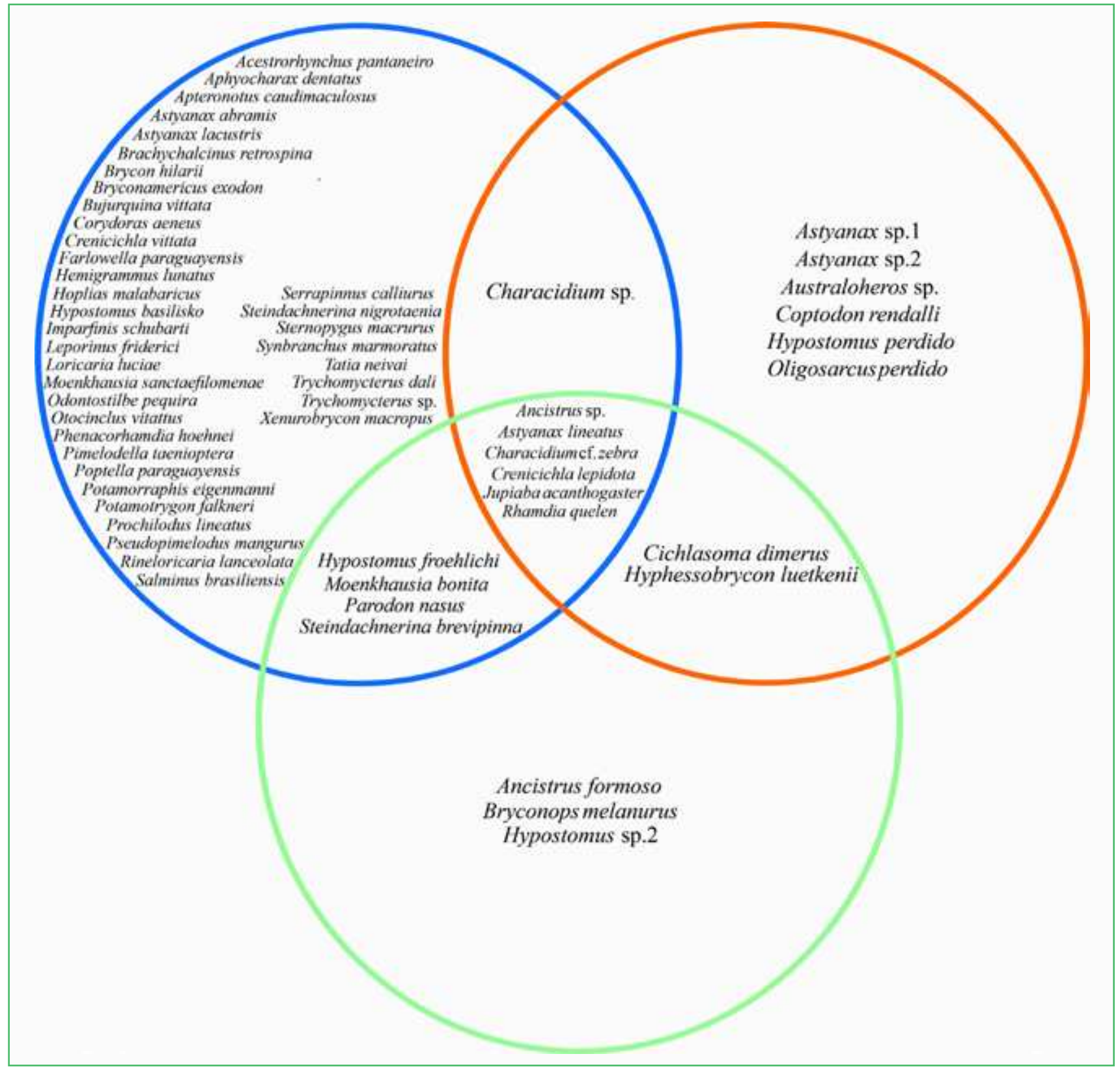

A similaridade foi maior entre as comunidades dos rios Formoso e Perdido $(J=0,38)$, menor entre os rios Salobra e Perdido $(J=0,12)$ e intermediária, entre os rios Salobra e Formoso $(J=0,19)$. Os índices indicam baixo compartilhamento de espécies entre os sistemas. Apenas seis espécies foram registradas nas três drenagens, com ampla distribuição na área do PNSB.

Quanto à ocorrência de espécies novas, seis registros foram de táxons não descritos, três registrados apenas na bacia do rio Perdido (Astyanax sp.1, Astyanax sp.2, Australoheros sp.), um apenas no Formoso (Hypostomus sp.2) e dois compartilhados entre mais de uma bacia (Ancistrus sp. e Characidium sp.).

Todas as espécies são nativas da bacia do alto Paraguai, com exceção de Coptodon rendalli, registrada no alto curso do rio Perdido. 


\section{Ameaças à conservação}

A ictiofauna associada às cabeceiras de riachos da Serra da Bodoquena está submetida a ameaças decorrentes de atividades antrópicas deletérias. Entre os problemas ambientais registrados durante as campanhas da AER destacam-se as queimadas, a permanência de gado em algumas áreas, o que intensifica o pisoteio marginal e assoreamento dos riachos, além da presença de espécie exótica (Coptodon rendalli) (Tabela 1 e Figura 13). Outra grande ameaça refere-se à não regularização fundiária de grande parte da UC. A estes devem ser acrescentados impactos potenciais a partir do entorno do PNSB, entre os quais as atividades de mineração, principalmente extração de calcário, o desmatamento, o avanço de grandes monoculturas sobre a região serrana e a intensificação da pecuária.

\section{Discussão}

A representatividade de Characiformes e Siluriformes registrada no PNSB segue o padrão encontrado em drenagens sul-americanas (LANGEANI et al., 2007; POLAZ et al., 2014; FROEHLICH et al., 2017), com Characidae e Loricariidae as famílias mais ricas em espécies. Entre os Characiformes predominaram espécies de pequeno porte (comprimento total inferior a $15 \mathrm{~cm}$ ), principalmente Characidae e Curimatidae, habitantes de pequenos volumes de água e habilitadas a explorar recursos alimentares diversos. Astyanax lineatus foi o caracídeo mais abundante e constante no rio Salobra e o segundo na bacia do rio Perdido. A sua abundância em riachos do PNSB, incluindo áreas degradadas, deve-se à grande plasticidade trófica (TERRA; SABINO, 2007); a elevada plasticidade

FIGURA 13: Impactos observados no PNSB e entorno imediato: a. Sinais de pisoteio por gado em margem de córrego; b. Área queimada no banhado do Perdido, na estiagem, a montante de seu ingresso no PNSB; c. Margem de rio invadida por bambus; d. Leito de córrego assoreado, na estiagem, em área vizinha ao PNSB.




ecológica também foi observada por Mehanna e Penha (2011), em riachos da Chapada dos Guimarães, Mato Grosso. Os lambaris $A$. lineatus e $A$. lacustris têm grande habilidade em saltar cachoeiras ou pequenas quedas, $o$ que também pode contribuir para ampliar sua área de vida nos rios e riachos do PNSB.

O lambari-vírgula Hyphessobrycon luetkeni foi a espécie de maior abundância no rio Perdido, onde ocorreu principalmente nos riachos e na área do banhado. Trata-se de espécie com ampla distribuição, ocorrendo nas bacias do Paraná, Paraguai, Uruguai, sistema Laguna dos Patos e drenagens costeiras do sul e sudeste (MALABARBA et al., 2013a). Na Laguna dos Patos, RS, fêmeas maduras da espécie foram encontradas durante quase todo o ano, com pico reprodutivo na primavera e no verão (MALABARBA et al., 2013b). Tal amplitude reprodutiva, aliada à ingestão de itens autóctones (insetos, microcrustáceos e algas) (ROA-FUENTES, 2011) e à preferência por ambientes calmos e vegetados, pode favorecer sua ocorrência e abundância no banhado do Perdido.

A segunda família com maior riqueza, Loricariidae, teve predomínio de Ancistrus sp., a segunda espécie mais abundante no rio Salobra (cerca de $20 \%$ das capturas), mas com ocorrência acidental no Perdido. Quatro espécies de Hypostomus também foram registradas: H. basilisko, $H$. froehlichi, $H$. perdido e Hypostomus sp.2. Em riachos da região noroeste de São Paulo, Casatti et al. (2010) observaram que a ocorrência de Hypostomus é influenciada pela extensão das corredeiras e qualidade da floresta ripária. Assim, é provável que a boa qualidade das matas ripárias da maioria dos riachos do PNSB, somada à disponibilidade de habitats com substrato rochoso, sejam determinantes na ocorrência de Hypostomus e outros loricarídeos, principalmente nas drenagens do Salobra, onde as corredeiras são rasas e as quedas pequenas. $\mathrm{Na}$ calha do Perdido, ao contrário, os poções são muito profundos, geralmente com profundidades maiores que seis metros, e o fundo é lamoso, devido à deposição de material; tais condições talvez possam influenciar na menor riqueza do grupo nesta drenagem.

No PNSB estão as localidades-tipo de seis espécies: Oligosarcus perdido e Hypostomus perdido, ambas no rio Perdido; Trichomycterus dali, na caverna Saracura; Ancistrus formoso, no Buraco do Ducho; Hypostomus basilisko e $H$. froehlichi, no córrego Salobrinha, além de Australoheros sp., conhecido até o momento no rio Perdido. Apesar de não situada dentro do PNSB, a localidade-tipo de Moenkhausia bonita encontra-se próxima ao seu limite leste (“Aquário Municipal”, rio Formoso). Isto reforça a necessidade de conservação de uma área que abriga localidades-tipo importantes na taxonomia dessas espécies.

Quase todas as espécies de Oligosarcus estão restritas a habitat reofílico de cabeceiras, em terrenos de maior altitude (MENEZES, 1987; RIBEIRO; MENEZES, 2015). No caso de Oligosarcus perdido, as únicas áreas com registro da espécie são o alto curso do rio Perdido (localidade-tipo) e as cabeceiras do rio Cuiabá, mostrando uma distribuição disjunta cujas justificativas remontam a eventos geológicos de mais de 2,5 m.a. (RIBEIRO; MENEZES, 2015). Na Serra da Bodoquena, $O$. perdido ocorre em baixa abundância (RIBEIRO et al., 2007), restrito à região a montante de um sumidouro localizado ao sul do PNSB, o que representa um agravante em termos de risco de extinção.

Em riachos do Arkansas, Lonzarich et al. (2000) observaram que a extensão e dinâmica de corredeiras podem interferir no movimento ascendente dos peixes, contribuindo para seu relativo isolamento dentro de poções. Uma hipótese a ser estudada é que a elevada ocorrência de espécies exclusivas, principalmente no rio Perdido (seis entre 15 espécies), pode estar influenciada pela existência de fatores que favorecem o isolamento das populações, como as grandes quedas e sumidouros, que podem diminuir a vagilidade dos indivíduos, como observado em Oligosarcus perdido.

Considerando o que se conhece até o momento, sete espécies registradas no PNSB são endêmicas da Serra da Bodoquena: Hypostomus basilisko, H. formoso, H. froehlichi, Ancistrus formoso, Australoheros sp., Trichomycterus dali e Trichomycterus sp.

Segundo Cordeiro et al. (2013), existem duas espécies troglóbias já descritas na Serra da Bodoquena (Ancistrus formoso e Trichomycterus dali) e pelo menos mais três ainda não descritas (Ancistrus sp., Rhamdia 
sp. e Trichomycterus sp.). Na presente lista optamos por incluir apenas três delas: A. formoso e Trichomycterus sp., registradas dentro do PNSB e na coleção ZUFMS, e T. dali, coletada por pesquisadores da UFMS. As outras duas espécies foram coletadas em cavernas associadas ao baixo curso do rio Salobra, fora da região de cabeceiras que identificam o PNSB. No entanto, é possível que estudos futuros possam confirmar suas ocorrências dentro do PNSB. Ancistrus formoso e T. dali constam na lista de espécies ameaçadas de extinção (MMA, 2014), categoria VU, critério D2 (Vulnerável, população pequena/distribuição muito restrita).

A tilápia Coptodon rendalli, de origem africana (ARCIFA; MESCHIATTI, 1996), é a única espécie exótica registrada até o momento no PNSB, com ocorrência confirmada no alto curso do rio Perdido, incluindo o banhado. Segundo moradores locais, sua introdução na região foi acidental, entre o final da década de 1980 - início de 1990, a partir do rompimento de um açude de criação de tilápias de uma fazenda, em razão de chuvas intensas, quando atingiram o rio Perdido. Nas campanhas da AER, juvenis da espécie foram capturados nesse rio, embora em baixa ocorrência. Em incursão posterior à região (novembro de 2017), Vilela e Carvalho (observação pessoal) observaram muitos indivíduos adultos na calha do rio Perdido, além de jovens e adultos no banhado, o que indica seu efetivo estabelecimento na bacia, favorecido pela natureza semilêntica do alto curso, similar ao seu habitat natural (AGOSTINHO et al., 2007). Sua presença pode representar riscos para as espécies nativas, uma vez que sua dieta inclui, entre outros itens, ovos, larvas e alevinos de peixes (ZAGANINI, 2009), e é uma invasora de alto potencial colonizador (VITULE et al., 2009). De acordo com Agostinho et al. (2007), em reservatórios brasileiros, a tilápia pode diminuir o recrutamento de espécies nativas, por competição por espaço ou por recursos alimentares, o que pode até mesmo levar tais espécies à extinção. Zaganini (2009) registra impactos da tilápia sobre populações de outros ciclídeos nativos, o que nos alerta para possíveis riscos a Australoheros sp., espécie não descrita e endêmica desta drenagem.

Froehlich (2010) encontrou 42 espécies apenas na microbacia do córrego Salobrinha, incluindo trechos fora do PNSB. Casatti et al. (2010), em riachos situados fora do PNSB e sob impactos urbanos e rurais, registraram 36 espécies, dez delas não amostradas neste trabalho. Costa (2015) descreveu Neofundulus rubrofasciatus coletada em poça temporária na planície de inundação do rio Salobra. Assim, é muito provável que novas espécies sejam acrescentadas à lista aqui apresentada, à medida que se ampliem as amostragens em áreas do PNSB ainda pouco investigadas, como as cabeceiras dos rios da Prata, Olaria e Formoso, e até mesmo a bacia do Perdido, por ser bem extensa e diversificada.

\section{Ameaças e recomendações para conservação}

De acordo com Sallun Filho et al. (2004), as lavras de calcário promovem alteração da paisagem e maior desmatamento, além de aumento significativo da turbidez da água pela lixiviação/escoamento dos sedimentos para os mananciais. Vestena et al. (2002) alertam para o uso de explosivos nas lavras, que podem causar trincas e aumentar o risco de colapso de solo e rochas, onde existem cavidades subterrâneas. Assim, as minerações, mesmo que ainda mantenham relativa distância do PNSB, podem representar um risco potencial à qualidade das águas e sua fauna associada, notadamente a troglóbia e as espécies associadas ao substrato, como os cascudos, caso as novas concessões avancem em direção ao entorno da UC.

$\mathrm{O}$ rápido avanço de monoculturas no planalto da Serra da Bodoquena promove maior desmatamento, instalação de processos erosivos, alteração na compactação do solo e risco de contaminação das águas superficiais e subterrâneas com agrotóxicos. Nesta região cárstica a percolação é rápida (VESTENA et al., 2002) e pode contaminar os aquíferos em pouco tempo, com o agravante da elevada persistência de muitas formulações.

Nas fazendas de pecuária extensiva, a substituição da vegetação arbórea por gramíneas altera a ciclagem de nutrientes e expõe o solo à ação erosiva, acelerando o assoreamento das drenagens, como se pode observar principalmente na bacia do rio Salobra. Além disso, altera as condições de habitat e pode eliminar trechos de fundos rochosos e águas correntes, assim como 
a fauna associada a esses ambientes. Exemplo disso é a ausência de Neofundulus rubrofasciatus na localidade-tipo transformada em matriz de monocultura (COSTA, 2015). O pisoteio do gado nas margens dos riachos também promove danos, e.g., nos locais de desova de determinadas espécies de peixes, além de causar turvamento da água. Associadas às atividades agropecuárias, as queimadas representam sério risco ambiental ao PNSB, em razão da elevada suscetibilidade da vegetação, sobretudo das matas secas. Especificamente para os peixes, as queimadas podem destruir a floresta ripária, fonte básica de alimentos, nutrientes e abrigo, e facilitar a erosão das margens.

Até 2016, apenas 18,34\% da área do PNSB haviam sido efetivamente adquiridas. Enquanto a indenização não ocorre, os proprietários têm permissão para manter as atividades que já exerciam antes da criação do PNSB (PELLEGRINI, 2016). O Conselho Gestor da UC, estabelecido desde 2005, vem atuando para acelerar as negociações fiscais e judiciais, ao mesmo tempo em que desenvolve programas de educação ambiental para a população local. O retardo na finalização dos processos de aquisição dificulta os acordos para medidas de proteção, inclusive na área de amortecimento, e expõe a UC ao risco de perdas de espécies por degradação. Em 2019, a $4^{\text {a }}$ Vara da Justiça Federal de Campo Grande havia suspendido $80 \%$ da área do PNSB, mas o Tribunal Regional Federal da $3^{\mathrm{a}}$ Região acatou os argumentos do Ministério Público Federal e cassou decisão liminar que reconhecia a caducidade do decreto que criou o PNSB (http://www.mpf.mp.br/ms/sala-de-imprensa/docs/2019/ decisao_trf3.pdf). Isso evidencia a necessidade de regularização da área como mantenedora de uma diversidade biótica única.

Entre as ações gerais para ampliar a proteção ambiental do PNSB, enfatiza-se a necessidade de: efetiva preservação das Áreas de Preservação Permanente e Reservas Legais; orientação para tratamento biológico de esgotos em fazendas e pousadas e monitoramento das atividades mineradoras e agropecuárias no entorno do PNSB; reforço nas iniciativas em educação ambiental e sensibilização da população local para que também sejam agentes na conservação; fiscalização efetiva da área, com pessoal técnico preparado; regularização fundiária e investimentos em infraestrutura da UC, que permita e incentive a visitação pública e o desenvolvimento de pesquisas no PNSB.

Entre as pautas para pesquisa destaca-se a necessidade de estudos sobre a presença de Coptodon rendalli no rio Perdido e outras drenagens, que podem auxiliar na busca por medidas paliativas para os potenciais impactos da espécie sobre peixes nativos. Investir em Unidades de Conservação é condição fundamental para garantir que, pelo menos dentro dessas áreas, tenhamos preservada uma parte da nossa rica e única biodiversidade.

\section{Agradecimentos}

Este trabalho foi parcialmente desenvolvido durante a Avaliação Ecológica Rápida do PNSB, por isso agradecemos ao ICMBio, nas pessoas de MSc. Ivan Salzo e Dr. Reuber Albuquerque Brandão, pelo convite para participar deste estudo. Também agradecemos a Lívia M. Cordeiro, Marcel R. Cavallaro, Nereida V. A. de Almeida, Ottilie C. Forster e Renata D. Vargas, pela participação nas coletas de campo. Especialmente somos gratos aos soldados do Exército Brasileiro, Batalhão de Fronteira MS, pelo indispensável apoio logístico em campo, e aos proprietários das fazendas, pela permissão de uso das sedes como ponto central de apoio. A Luiz F. C. Tencatt, pelo apoio e identificação de alguns táxons. À UFMS, pelo apoio institucional.

\section{Referências}

AGOstinho, A. A.; GOMES, L. C.; PELICICE, F. M. Ecologia e manejo de recursos pesqueiros em reservatórios do Brasil. Maringá: EDUEM, 2007. 501 p.

ARCIFA, M. S.; MESCHIATTI, A. J. Tilapia rendalli in the Lake Monte Alegre, a case of planktivory. Acta Limnologica Brasiliensia, Rio Claro, v. 8, p. 221-229, 1996.

BENINE, R. C.; CASTRO, R. M. C.; SABINO, J. Moenkhausia bonita: A new small characin fish from the Rio Paraguay Basin, Southwestern Brazil (Characiformes: Characidae). Copeia, Lawrence, v. 1, p. 68-73, 2004.

BOGGIANI, P. C. Geologia da Bodoquena. In: SCREMIN-DIAS, E.; POTT, V. J.; HORA, R. C.; SOUZA, P. R. (Ed.). Nos jardins submersos da Bodoquena: guia para identificação de plantas aquáticas de Bonito e região. Campo Grande: Editora da UFMS, 1999. p. 10-23. 
BOGGIANI, P. C.; FAIRCHILD, T. R.; COIMBRA, A. M. O Grupo Corumbá (Neoproterozóico - Cambriano) na região central da Serra da Bodoquena (Faixa Paraguai), Mato Grosso do Sul. Revista Brasileira de Geociências, Curitiba, v. 23, n. 3, p. 301-305, 1993.

BRASIL. Lei no 9985, de 18 de julho de 2000. Regulamenta o art. $225, \S 1$ 을 incisos I, II, III e VII da Constituição Federal, institui o Sistema Nacional de Unidades de Conservação da Natureza e dá outras providências. Diário Oficial da União. Brasília, DF. 2000. Disponível em <http://www.planalto.gov.br/ccivil_03/LEIS/ L9985.htm>.

BRITSKI, H. A.; SILIMON, K. Z. S.; LOPES B. S. Peixes do Pantanal: manual de identificação. Brasília: Embrapa, 1999. 181 p. BRITSKI, H. A.; SILIMON, K. Z. S.; LOPES, B. S. Peixes do Pantanal: manual de identificação. 2. ed. Brasília: Embrapa Informação Tecnológica, 2007. 228 p.

CARVALHO, F. R.; VILELA, M. J. A.; SEVERO-NETO, F. Pequenos, únicos e desprotegidos: peixes endêmicos da bacia do alto Paraguai. Ciência Pantanal, Campo Grande, v. 4, p. 20-23, 2018.

CASATTI, L.; ROMERO, R. M.; TERESA, F. B.; SABINO, J.; LANGEANI, F. Fish community structure along a conservation gradient in Bodoquena Plateau streams, central West of Brazil. Acta Limnologica Brasiliensia, Rio Claro, v. 22, n. 1, p. 50-59, 2010 .

CORDEIRO, L. M.; BORGHEZAN, R.; TRAJANO, E. Distribuição, riqueza e conservação dos peixes troglóbios da Serra da Bodoquena, MS (Teleostei: Siluriformes). Distribution, richness and conservation of troglobitic fishes from Serra da Bodoquena, MS (Teleostei). Revista da Biologia, São Paulo, v. 10, n. 2, p. 2127, 2013.

COSTA, W. J. E. M. Taxonomy of the seasonal killifish genus Neofundulus in the Brazilian Pantanal (Cyprinodontiformes: Rivulidae). Vertebrate Zoology, Dresden, v. 65, n. 1, p. 15-25, 2015.

FERREIRA, F. S.; DUARTE, G. S. V.; SEVERO-NETO, F.; FROEHLICH, O.; SÚAREZ, Y. R. Survey of fish species from plateau streams of the Miranda River Basin in the Upper Paraguay River Region, Brazil. Biota Neotropica, Campinas, v. 17, n. 3, p. 1-9, 2017.

FROEHLICH, O. Ictiofauna de um córrego na Serra da Bodoquena: estrutura, variações longitudinal e temporal e efeitos sobre comunidades bentônicas. 2010. 97 f. Tese (Doutorado em Ecologia e Conservação) - Universidade Federal de Mato Grosso do Sul, Campo Grande. 2010.

FROEHLICH, O.; CAVALLARO, M.; SABINO, J.; SÚAREZ, Y. R.; VILELA, M. J. A. Checklist da ictiofauna do estado de Mato Grosso do Sul, Brasil. Iheringia, Série Zoologia, Porto Alegre, v. 107, n. suplementar, p. 1-14, 2017.

ICMBIO. Plano de manejo do Parque Nacional da Serra da Bodoquena. Encarte 2 - Descrição da Região da UC. 2013a. Disponível em <www.icmbio.gov.br/portal/images/stories/docsplanos-de-manejo/Encarte2_serra_do_bodoquena.pdf $>$.

ICMBIO. Plano de manejo do Parque Nacional da Serra da Bodoquena. Encarte 3 - Análise do PNSB. 2013b. Disponível em <www.icmbio.gov.br/portal/images/stories/docs-planos-demanejo/Encarte3_serra_do_bodoquena.pdf $>$.
LANGEANI, F.; CASTRO, R. M. C.; OYAKAWA, O. T.; SHIBATTA, O. S.; PAVANELli, C. S.; CASATTI, L. Diversidade da ictiofauna do Alto Rio Paraná: composição atual e perspectivas futuras. Biota Neotropica, Campinas, v. 7, n. 3, p. 181-197, 2007.

LONZARICH, D. G.; LONZARICH, M. R.; WARREN, J. R. ML. Effects of riffle length on the short-term movement of fishes among stream pools. Canadian Journal of Fisheries and Aquatic Sciences, Ottawa, v. 57, p. 1508-1514, 2000.

MALABARBA, L. R.; CARVALHO-NETO, P.; BERTACO, V. A.; CARVAlHO, T. P.; SANTOS, J. F.; ARTIOLI, L. G. S. Guia de identificação dos peixes da bacia do Rio Tramandaí. Porto Alegre: Ed. Via Sapiens, 2013a. 140 p.

MALABARBA, L. R.; FIALHO, C. B.; BERTACO, V. A.; CARVALHO, F. R.; DUFECH, A. P. S.; FERRER, J.; GIORA, J. Peixes. In: WITT, P. B. R. (Coord.). Fauna e flora da Reserva Biológica Lami José Lutzenberger. Porto Alegre: Secretaria Municipal do Meio Ambiente. 2013b. p. 146-184.

MATO GROSSO DO SUL. Avaliação ambiental estratégica do PRODETUR Nacional no estado de Mato Grosso do Sul. Polo Serra da Bodoquena. Campo Grande: Governo do Estado de Mato Grosso do Sul, 2014. 276 p.

MEHANNA, M.; PENHA, J. Fatores abióticos que afetam a distribuição do gênero Astyanax Baird \& Girard, 1854 em riachos de cabeceiras de Chapada dos Guimarães, bacia do Rio Cuiabá, Mato Grosso. Bioscience Journal, Uberlândia, v. 27, n. 1, p. 25137, 2011.

MENEZES, N. A. Três espécies novas de Oligosarcus Gunther,1864 e redefinição taxonômica das demais espécies do gênero (Osteichthyes, Teleostei, Characidae). Boletim de Zoologia da Universidade de São Paulo, São Paulo, v. 11, p. 1-39, 1987.

MENEZES, N.; FROEHLICH, O.; OYAKAWA, O.; WILLINK, P. W.; MACHADO-ALLISON, A.; CHERNOFF, B. Fishes collected and species new to science for each region sampled by the AquaRAP expedition to the Pantanal, Mato Grosso do Sul, Brazil, from August 25 to September 9, 1998. In: WILLINK, P. W.; CHERNOFF, B.; ALONSO, L. E.; MONTANBAULT, J. R.; LOURIVAL, R. (Ed.). A biological assessment of the aquatic ecossistems of the Pantanal, Mato Grosso do Sul, Brasil. Washington: Conservation International, 2000. p. 291-296. (RAP Bulletin of Biological Assessment, Vol. 18).

MMA - MINISTÉRIO DO MEIO AMBIENTE. Portaria No 445 de 17 de dezembro de 2014: atualização da lista de espécies de peixes e invertebrados aquáticos ameaçados de extinção. Brasília: Ministério do Meio Ambiente, no 245, Seção 1, 2014.

PELLEGRINI, F. Justiça extingue ação contra o Parque Nacional da Serra da Bodoquena. O Eco, 06 de julho de 2016. Disponível em $<$ http://www.oeco.org.br/noticias/justica-extingue-acao-contrao-parque-nacional-da-serra-da-bodoquena $>$.

POLAZ, C. N. M.; MELO, B. F.; BRITZKE, R.; RESENDE, E. K. R.; MACHADO, F. A.; FERRAZ DE LIMA, J.; PETRERE Jr., M. Fishes from the Parque Nacional do Pantanal Matogrossense, upper Paraguai River basin, Brazil. Check List, Rio Claro, v. 10, n. 1, p. 122-130, 2014.

REYS, P.; GALETTI, M.; MORELlATO, L. P. C.; SABINO, J. Fenologia reprodutiva e disponibilidade de frutos de espécies arbóreas em mata ciliar no rio Formoso, Mato Grosso do Sul. Biota Neotropica, Campinas, v. 5, n. 2, p. 1-10, 2005. 
RIBEIRO, A. C.; CAVALlARO, M. R.; FROEHLICH, O. Oligosarcus perdido (Characiformes, Characidae), a new species of freshwater fish from Serra da Bodoquena, upper Rio Paraguai basin, Brazil. Zootaxa, Auckland, v. 1560, p. 43-53, 2007.

RIBEIRO, A. C.; MENEZES, N. A. Phylogenetic relationships of the species and biogeography of the characid genus Oligosarcus Günther, 1864 (Ostariophysi, Characiformes, Characidae). Zootaxa, Auckland, v. 3949, n. 1, p. 41-81, 2015.

ROA-FUENTES, C. A. Estrutura ecomorfológica e trófica de peixes de riachos: comparação entre ambientes com diferentes graus de conservação e entre bacias hidrográficas. 2011. 157 f. Dissertação (Mestrado em Biologia Animal) - Universidade Estadual Paulista, São José do Rio Preto. 2011.

SABINO, J.; ANDRADE, L. P. Uso e conservação da ictiofauna na região de Bonito, Mato Grosso do Sul: o mito da sustentabilidade ecológica no rio Baía Bonita (Aquário Natural de Bonito). Biota Neotropica, Campinas, v. 3, n. 2, p. 1-9, 2003.

SABINO, J.; SAZIMA, I. Association between fruit-eating fish and foraging monkeys in western Brazil. Ichthyological Exploration of Freshwaters, München, v. 10, n. 4, p. 309-312, 1999.

SABINO, J.; TRAJANO, E. A new species of blind armoured catfish, genus Ancistrus, from caves of Bodoquena region, Mato Grosso do Sul, southwestern Brazil. Revue Française D'Aquariologie, Paris, v. 24, p. 73-78, 1997.

SALLUN FILHO, W.; KARMANN, I. Geomorphological map of the Serra da Bodoquena karst, west-central Brazil. Journal of Maps, London, v. 3, n. 1, p. 282-295, 2007.

SALLUN FILHO, W.; KARMANN, I.; BOGGIANI, P. C. Paisagens cársticas da Serra da Bodoquena (MS). In: MANTESSO-NETO, V.; BARTORELLI, A.; CARNEIRO, C. D. R.; BRITO-NEVES, B. B. (Ed.). Geologia do continente Sul-americano: evolução da obra de Fernando Flávio Marques de Almeida. São Paulo: Beca, 2004. p. 423-433.

SALLUN FILHO, W.; KARMANN, I.; BOGGIANI, P. C.; PETRI, S.; CRISTALLI, O. S.; UTIDA, G. A deposição de tufas quaternárias no estado de Mato Grosso do Sul: proposta de definição da Formação Serra da Bodoquena. Geologia USP, Série Científica, São Paulo, v. 9, n. 3, p. 47-60, 2009.

SCREMIN-DIAS, E.; POTT, V. J.; HORA, R. C.; SOUZA, P. R. Nos jardins submersos da Bodoquena: guia para identificação de plantas aquáticas de Bonito e região. Campo Grande: Editora da UFMS, 1999. $160 \mathrm{p}$.

SEVERO-NETO, F.; TERESA, F. B.; FROEHLICH, O. Ecomorphology and diet reflect the spatial segregation between two Siluriformes species inhabiting a stream of the Bodoquena Plateau, in Central Brazil. Iheringia série Zoologia, Porto Alegre, v. 105, n. 1, p. 62-68, 2015.

TENCATT, L. F. C.; ZAWADZKI, C. H.; FROEHLICH, O. Two new species of the Hypostomus cochliodon group (Siluriformes: Loricariidae) from the rio Paraguay basin, with a redescription of Hypostomus cochliodon Kner, 1854. Neotropical Ichthyology, Maringá, v. 12, n. 3, p. 585-602, 2014.

TERRA, L. C. C.; SABINO, J. Composição da ictiofauna de dois riachos, com diferentes graus de conservação, na bacia do rio Formoso, município de Bonito, Mato Grosso do Sul, Brasil. Ensaios e Ciência, Campo Grande, v. 1, n. 1, p. 49-58, 2007.

THOMAS, M. R.; RODRIGUEZ, M. S.; CAVALLARO, M. R.; FROEHLICH, O.; CASTRO, R. M. C. Loricaria luciae, a new species of whiptail catfish (Siluriformes: Loricariidae) from the Paraguay and lower Paraná River basins of southeastern South America. Zootaxa, Auckland, v. 3745, n. 3, p. 365-378, 2013.

UETANABARO, M.; SOUZA, F. L.; LANDGREF FILHO, P.; BEDA, A. F.; BRANDÃO, R. A. Anfíbios e répteis do Parque Nacional da Serra da Bodoquena, Mato Grosso do Sul, Brasil. Biota Neotropica, Campinas, v. 7, n. 3, p. 279-289, 2007.

UIEDA, V. S.; CASTRO, R. M. C. Coleta e fixação de peixes de riachos. Série Oecologia Brasiliensis, Rio de janeiro, v. 6, p. 1-22, 1999.

VAN DER LAAN, R.; ESCHMEYER, W. N.; FRICKE, R. Familygroup names. Disponível em <http://www.calacademy.org/ scientists/catalog-of-fishes-family-group-names/>.

VESTENA, L. R.; KOBIYAMA, M.; SANTOS, L. J. C. Considerações sobre gestão ambiental em áreas carste. RAEGA O espaço geográfico em análise, Curitiba, v. 4, n. 6, p. 81-94, 2002. VITULE, J. R. S.; FREIRE, C. A.; SIMBERLOFF, D. Introduction of non-native freshwater fish can certainly bad. Fish and Fisheries, Vancouver, v. 10, p. 98-108, 2009.

WILLINK, P. W.; CHERNOFF, B.; ALONSO, L. E.; MONTANBAULT, J. R.; LOURIVAL, R. (Ed.). A biological assessment of the aquatic ecossistems of the Pantanal, Mato Grosso do Sul, Brasil. RAP Bulletin of Biological Assessment 18. Washington: Conservation International. 2000.

ZAGANINI, R. L. Caracterização do regime alimentar de Oreochromis niloticus (Linnaeus, 1758) e Tilapia rendalli (Boulenger, 1897) na represa de Barra Bonita, Médio Rio Tietê, SP. 2009. 71 f. Dissertação (Mestrado em Ciências Biológicas Zoologia) - Universidade Estadual Paulista, Botucatu. 2009.

ZAWADZKI, C. H.; NARDI, G.; TENCATT, L. F. C. The crystalline waters of the Bodoquena Plateau revealed Hypostomus froehlichi (Siluriformes: Loricariidae), a new armored catfish from the rio Paraguay basin in Brazil. Zootaxa, Auckland, v. 4933, n. 1, p. 98-112, 2021.

ZAWADZKI, C. H.; TENCATT, L. F. C.; FROEHLICH, O. A new unicuspid-toothed species of Hypostomus Lacépède, 1803 (Siluriformes: Loricariidae) from the rio Paraguai basin. Neotropical Ichthyology, Maringá, v. 12, n. 1, p. 97-104, 2014. 